\title{
Rapid evolution of genome-wide gene expression and plasticity during saline to freshwater invasions by the copepod Eurytemora affinis species complex
}

\author{
Marijan Posavi ${ }^{1}$, Davorka Gulisija ${ }^{2}$, James Munro ${ }^{3}$, Joana Carneiro da Silva ${ }^{3}$, and Carol \\ Eunmi Lee ${ }^{1}$ \\ ${ }^{1}$ University of Wisconsin Madison \\ ${ }^{2}$ University of New Mexico \\ ${ }^{3}$ University of Maryland School of Medicine
}

June 28, 2020

\begin{abstract}
Saline migrants into freshwater habitats constitute among the most destructive invaders in aquatic ecosystems throughout the globe. However, evolutionary and physiological mechanisms underlying such habitat transitions remain poorly understood. To explore mechanisms of freshwater adaptation and distinguish between adaptive (evolutionary) and acclimatory (plastic) responses to salinity change, we examined genome-wide patterns of gene expression between ancestral saline and derived freshwater populations of the Eurytemora affinis species complex, reared under two different common-garden conditions (0 vs. 15 PSU). We found that evolutionary shifts in gene expression (between saline and freshwater inbred lines) showed far greater changes and were more widespread than acclimatory responses to salinity (0 vs. 15 PSU). Most notably, many genes showing evolutionary shifts in gene expression across the salinity boundary were associated with ion transport function, with inorganic cation transmembrane transport forming the largest Gene Ontology category. Of particular interest was the sodium transporter, the $\mathrm{Na}^{+} / \mathrm{H}^{+}$antiporter (NHA) gene family, which was discovered in animals relatively recently. A few key ion regulatory genes, such as NHA paralog $\# 7$, demonstrated concordant evolutionary and plastic shifts in gene expression, suggesting the evolution of ion transporter plasticity and function during rapid invasions into novel salinities. Moreover, freshwater invasions were associated with the evolution of reduced plasticity in the freshwater population, again for the same key ion transporters, consistent with the predicted evolution of canalization following adaptation to stressful conditions. Our results have important implications for understanding invasion mechanisms by some of the most widespread invaders in aquatic habitats.
\end{abstract}

\section{INTRODUCTION}

Of the large number of species that are introduced into novel environments, only a very small percentage survive and become established (Williamson \& Fitter, 1996). Of these invaders, those that can breach major habitat boundaries comprise a disproportionate number of successful contemporary invaders on earth (Lee, 2010; Lee \& Bell, 1999; Lee \& Gelembiuk, 2008). For example, many formerly brackishwater species now dominate freshwater ecosystems throughout the world (Cristescu et al., 2001; Gelembiuk, May, \& Lee, 2006; Marsden, Spidle, \& May, 1995; Marsden, Spidle, \& May, 1996; May et al., 2006), despite being inefficient osmoregulators in freshwater habitats (Dietz et al., 1996; Lee et al., 2013). These saline immigrants include some of the most destructive invaders in freshwater habitats, such as zebra mussels, quagga mussels, the fishhook water flea, and many invasive amphipods (Cristescu et al., 2001; Dermott et al., 1998; Gelembiuk et al., 2006; MacIsaac, Grigorovich, \& Ricciardi, 2001; May et al., 2006; Rewicz et al., 2015; Witt, Hebert, \& Morton, 1997). Such brackishwater species are invading freshwater habitats in disproportionately high numbers relative to expectations based on propagule pressure and transport opportunity (Casties, Seebens, 
\& Briski, 2016). What are the physiological and evolutionary mechanisms that enable such radical habitat transitions to occur on rapid contemporary time scales?

In an intriguing example, the Eurytemora affinis species complex (Lee, 2000; Lee \& Frost, 2002) is a dominant estuarine and saltmarsh copepod that has invaded freshwater habitats multiple times independently over the past $\sim 80$ years on three continents (Lee, 1999). During the invasions from saline to freshwater environments, populations of this copepod complex have experienced rapid evolution of physiological tolerance and performance in response to drastic changes in salinity (Lee et al., 2011; Lee et al., 2013; Lee \& Petersen, 2002, 2003; Lee, Posavi, \& Charmantier, 2012; Lee, Remfert, \& Chang, 2007; Lee, Remfert, \& Gelembiuk, 2003; Posavi, Larget, Gelembiuk, \& Lee, 2014). For instance, prior studies have found evolutionary shifts in ion transporter function associated with saline to freshwater invasions, such as shifts in activity and expression of the ion transporters $\mathrm{V}$-type $\mathrm{H}^{+}$-ATPase (VHA) and $\mathrm{Na}^{+} / \mathrm{K}^{+}$-ATPase (NKA) (Lee et al., 2011). Moreover, a recent population genomic analysis of the E. affinis complex revealed that multiple freshwater invasions show parallel signatures of selection at genomic regions containing key ion transporters, such as paralogs of $\mathrm{Na}^{+} / \mathrm{H}^{+}$antiporter, $\mathrm{Na}^{+} / \mathrm{K}^{+}$-ATPase, andalpha-Carbonic Anhydrase (Stern \& Lee, 2020). Thus, our prior results in this system indicate that evolution of ionic regulation is likely to be an important mechanism for low-salinity adaptation following freshwater invasions.

However, mechanisms of ion uptake under freshwater conditions are not well understood for any organism and are controversial, making physiological mechanisms involved in freshwater adaptation uncertain. Several comprehensive models of ion uptake from fresh water have been proposed, but none have been conclusively confirmed (see Discussion, Section 4.2) (Charmantier et al., 2009; Evans \& Clairborne, 2009; Kumai \& Perry, 2012; McNamara \& Faria, 2012). For instance, the identities of the secondary transporters responsible for $\mathrm{Na}^{+}$uptake have remained unclear (Charmantier et al., 2009; Evans \& Clairborne, 2009; Kumai \& Perry, 2012; McNamara \& Faria, 2012). This ion transporter has been hypothesized to be the $\mathrm{Na}^{+}$channel (McNamara \& Faria, 2012) or the $\mathrm{Na}^{+} / \mathrm{H}^{+}$exchanger (NHE) (Parks, Tresguerres, \& Goss, 2008; Shetlar \& Towle, 1989). Alternatively, this transporter could even be the $\mathrm{Na}^{+} / \mathrm{H}^{+}$-antiporter (NHA), which was discovered in animals relatively recently (Rheault et al., 2007; Xiang et al., 2012) including in the human kidney (Kondapalli et al., 2012).

Given the uncertainties regarding mechanisms involved in freshwater adaptation, the goal of this study was to explore evolutionary shifts in gene expression between ancestral saline and freshwater invading populations of the E. affinis complex on a genome-wide scale. Our specific goals were to determine genomic patterns of (1)evolutionary shifts (heritable shifts) in gene expression between the ancestral saline and freshwater invading populations and (2)acclimatory changes (resulting from phenotypic plasticity) in gene expression between salinities (0 PSU vs . 15 PSU conditions) within each of the saline and freshwater populations. We also wanted to(3) explore functional categories of genes that showed evolutionary and acclimatory shifts in expression associated with salinity change. Given our prior results, we predicted that ion transporter genes would emerge as a dominant category showing evolutionary and acclimatory changes in expression. Moreover, we were especially interested in identifying the elusive $\mathrm{Na}^{+}$transporter likely responsible for $\mathrm{Na}^{+}$ uptake from low salinity environments.

Additionally, according to Lande's model (2009) and Waddington's argument (1953), the evolution of plasticity could accelerate phenotypic adaptation during extraordinary environmental change. During the initial stages of invasion into a novel environment, the evolution of plasticity could arise via selection favoring the more extreme phenotype, that expresses greater plasticity in the novel environment, resulting in steeper reaction norm slope. Such a process would enable invasive populations to survive radical habitat shifts and avoid extinctions (Lande, 2009; Waddington, 1953). However, over longer periods of time, evolution of canalization is expected, as plasticity would no longer be favored in the freshwater environment and would be lost over time (Lande, 2009). Given this model, our additional goals were to(4) determine whether the magnitude and direction of plasticity in gene expression were correlated with evolutionary responses, indicating shared mechanisms of acclimation and adaptation and the presence of an acclimatory response that could be favored by selection during invasions, and also (5) examine whether plasticity in gene expression 
has evolved following freshwater invasions.

A genome-wide analysis of gene expression constitutes a comprehensive approach toward elucidating the relative contribution of regulatory adaptation to rapid evolution during invasions into novel habitats. Thus, we employed an RNA-seq approach to compare transcriptome-wide patterns of gene expression between ancestral saline and derived freshwater populations of the copepod E. affinis complex. To this end, we conducted two $2 \times 2$ factorial common-garden experiments using independently derived saline and freshwater inbred lines reared under contrasting salinity conditions ( 0 vs . 15 PSU). The controlled common-garden experimental design was a key strength of this study, making it possible to distinguish between geneticallybased changes due to evolutionary divergence between the saline and freshwater lines (Goal \#1) versus environmentally-induced differences in gene expression due to acclimation to different salinities (Goal \#2).

In general, the capacity to respond to salinity change is now a topic of major concern, given the rapid decline in ocean salinity in many coastal regions due to large volumes of ice melt and changes in global precipitation patterns (Durack, Wijffels \& Matear, 2012; Bintanja et al., 2015). As this study explores evolutionary shifts occurring on contemporary time scales, of only decades from saline into freshwater habitats, results here could advance our understanding of evolutionary mechanisms underlying responses to rapid global environmental change. Furthermore, this and our other related studies are providing insights into mechanisms of ion uptake under freshwater conditions and fundamental principles of ion transport physiology (Stern \& Lee, 2020; Gerber et al., 2016; Johnson et al., 2014; Lee et al., 2011; Lee et al., 2012). The evolutionary shifts were of particular interest in this study because they might result from natural selection acting on the traits that enable freshwater adaptation. Physiological studies on osmoregulation have tended to focus on acclimatory responses, rather than on evolutionary shifts examined under common-garden conditions (see Discussion).

Moreover, studies on the copepod E. affinis species complex are of profound environmental importance, given that this copepod is a dominant grazer of algae throughout coastal waters of the Northern Hemisphere. This copepod forms an enormous biomass in estuaries, with census sizes in the billions (Simenstad \& Cordell, 1985; Winkler et al., 2005), and supports some of the world's most important fisheries, such as herring, anchovy, salmon, and flounder (Kimmel, Miller, \& Roman, 2006; Livdāne et al., 2016; Shaheen et al., 2001; Viitasalo, Flinkman, \& Viherluoto, 2001; Winkler et al., 2003). Thus, the evolutionary capacity of this copepod is of utmost importance for the preservation of ecosystem health and integrity in a changing world.

\section{MATERIALS AND METHODS}

\subsection{Population sampling and inbreeding}

For our study, we used inbred lines derived from saline and freshwater populations of the copepod Eurytemora affinis species complex from the St. Lawrence drainage system, specifically from the Atlantic clade, also referred to as Eurytemora carolleeae (Alekseev \& Souissi, 2011). The freshwater populations in the Great Lakes were transported (likely via ship ballast water) from the saline St. Lawrence estuary 60 years ago (Engel, 1962; Lee, 1999; Winkler, Dodson, \& Lee, 2008). We produced four inbred lines by performing full-sib mating for 30 generations. We generated two saline inbred lines (SW1 and SW2) independently from the ancestral saline population in Baie de L'Isle Verte salt marsh of the St. Lawrence estuary, Quebec, Canada (48 $\left.00^{\prime} 14^{\prime \prime} \mathrm{N}, 69^{\circ} 25^{\prime} 31^{\prime \prime} \mathrm{W}\right)$, collected in 2006. This salt marsh experiences seasonally fluctuating salinities of 5 to 40 PSU (PSU [?] parts per thousand salinity). We inbred these lines at 15 PSU salinity. We also generated two freshwater inbred lines (FW1 and FW2) independently from the freshwater invading population in Lake Michigan at Racine Harbor, WI, USA (42deg43'46" N, 87deg46'44" W), collected in 2006. We inbred and maintained the freshwater lines under freshwater conditions (0 PSU, conductivity $\sim 300 \mu \mathrm{S} / \mathrm{cm})$. Using inbred lines reduced genetic variation within the population comparisons and increased statistical power to detect differentially-expressed (DE) genes between the saline and freshwater lines.

\subsection{Common-garden experiments}

We employed a common-garden approach (Figure 1 ) to disentangle the effects of (1) heritable (evolutionary) differences between the saline and freshwater populations (Goal 1) from (2)environmentally induced 
changes (phenotypic plasticity) in gene expression at different salinities (0 and 15 PSU) (Goal 2). A classical common-garden approach is required to determine evolutionary differences in gene expression between the populations that were collected from different habitats (Mërila \& Hendry, 2014). This approach involves rearing different populations under identical conditions for 1-2 generations to first remove effects of developmental acclimation to salinities of the native habitats. This step is necessary because rearing conditions during development significantly influence the physiological tolerances of adults (Lee \& Petersen, 2003).

We performed two replicate common-garden reaction norm experiments, each consisting of a $2 \times 2$ factorial design, where we compared expression patterns of the FW and SW inbred lines at both 0 and 15 PSU (seeFigure 1 and next paragraph). In replicate Experiment 1, we contrasted patterns of gene expression between the freshwaterFW2 and saline SW1 inbred lines (3 biological replicates each). In Experiment 2 , we compared gene expression patterns between the freshwater FW1 (2 biological replicates) and saline SW2 inbred lines (3 replicates). To minimize consideration of differentially-expressed (DE) genes that might have evolved due to genetic drift, we only considered genes that were DE in both experiments, representing repeated independent comparisons between distinct inbred lines.

In terms of experimental design (Figure 1 ), we reared the replicate saline (SW1, SW2 ) and freshwater (FW1, FW2 ) inbred lines under common-garden conditions, first at 5 PSU and then at the following generation at two contrasting salinities (0 and 15 PSU ). Specifically, to remove the effects of developmental acclimation to native habitat salinities, we first placed juveniles from both the saline and freshwater lines at 5 PSU and reared them to adulthood (Figure 1a). We then allowed these adults to produce offspring and reared them at 5 PSU until they metamorphosed into juveniles (copepodids) (Figure 1b ). The intermediate salinity 5 PSU is well-tolerated by both saline and freshwater populations (Lee et al. 2003, 2007, 2011, 2013). We then split the juvenile samples from each line (reared at 5 PSU) and reared them at two different salinities (0 and 15 PSU) until adulthood (Figure 1c and 1d ). Thus, removing the effects of prior acclimation to different native salinities and then comparing different inbred lines at the same salinities (either at 0 or 15 PSU) allowed us to observe evolutionary differences alone between the inbred lines (FW/SW , evolutionary adaptation, Goal 1). On the other hand, comparisons between gene expression at contrasting conditions for each of the inbred lines allowed us to infer environmentally induced differences in expression across salinities within each line (0 PSU/15 PSU, phenotypic plasticity, i.e., acclimation, Goal 2).

Prior to the common-garden experiment, we maintained both saline and freshwater inbred lines at their native control salinities (15 and 0 PSU, respectively). For the freshwater inbred lines we filtered lake Michigan water (conductivity $\sim 300 \mu \mathrm{S} / \mathrm{cm}, 0$ PSU), whereas for saline inbred lines we made 15 PSU water using deionized water and Instant Ocean ${ }^{\circledR}$. Prior to and during the experiment, we fed the freshwater alga Rhodomonas minuta to copepods reared at 0 PSU, and the saltwater alga Rhodomonas salina to copepods reared at 15 PSU, and a 1:1 mixture of $R$. minuta and $R$. salina to copepods reared at 5 PSU (Figure 1a and $\mathbf{1 b}$ ). We maintained the copepod cultures and experimental treatments at $12^{\circ} \mathrm{C}$, on a $15 \mathrm{~L}: 9 \mathrm{D}$ light cycle.

To remove bacterial and fungal contamination prior to RNA extraction, we applied an antibiotic cocktail that we tested in prior studies (Eyun et al., 2017). Starting 2 weeks prior to RNA extraction, the copepods were treated with Primaxin ${ }^{\circledR}(20 \mathrm{mg} / \mathrm{L})$, D-amino acids to remove biofilm $(10 \mu \mathrm{M}$ of D-methionine, D-leucine and D-tryptophan and $5 \mu \mathrm{M}$ D-tyrosine), and Voriconazole $(0.5 \mathrm{mg} / \mathrm{L})$ every $3-4$ days. For the final 24 hours prior to RNA extraction, copepods were starved and treated with $120 \mu \mathrm{L} / \mathrm{L}$ of 6.0 -micron copolymer microsphere beads (Thermo Scientific cat\# 7505A, Fremont, CA) to clear the gut microbiome.

\subsection{RNA extraction and sequencing}

We performed whole-transcriptome shotgun sequencing (RNA-seq) of saline and freshwater inbred lines of the copepod E. affinis complex. Once the copepods reached adulthood (see previous section), we extracted total RNA from whole bodies of 50 copepods (25 females and 25 males) per sample (Figure 1d ). We extracted total RNA using Trizol reagent (Ambion RNA, Carlsbad, CA) and Qiagen RNeasy Mini Kit for purification (Qiagen cat\# 74104, Valencia CA).

We then sequenced three biological replicates per inbred line (2 biological replicates in the case of FW1) 
(Figure 1e ). We constructed strand-specific Illumina RNA-seq libraries (Parkhomchuk et al., 2009) of polyA purified mRNA using the TruSeq RNA Sample Prep kit (Illumina, San Diego, CA). We sequenced the samples using the Illumina HiSeq 2000 platform at the Institute for Genome Sciences at the University of Maryland School of Medicine and generated $101 \mathrm{bp}-$ long paired-end read data. We sequenced 22 RNA samples (4 inbred lines x 2 salinities x 3 replicates [2 replicates for FW1]) in three batches (on three different dates) (Supplementary Table 1 ).

\subsection{Data processing and statistical analyses}

An overview of the protocol used to detect DE genes is provided inFigure S1 . In the initial step, the Institute for Genome Sciences' QC pipeline was used to screen $250 \mathrm{~K}$ random sequence reads from each sample against a local install of the NCBI nucleotide database to generate a rough assessment of taxonomic composition and ensure provenance of the sample. Each sample was then run through the data processing pipeline to detect the presence of adaptor sequences or low read quality (threshold of $>2$ consecutive bases with $\mathrm{Q}<20)$ using FastQC (http://www.bioinformatics.babraham.ac.uk/projects/fastqc/). When necessary, reads were trimmed with Trimmomatic, Version 032 (Bolger, Usadel, \& Lohse, 2014). On average, $3.5 \mathrm{x}$ $10^{7}$ paired-end reads per sample passed these filtering steps.

To quantify transcript (gene) expression levels, we used an expectation maximization approach employing the RSEM (RNA-seq by Expectation Maximization) package (Li \& Dewey, 2011). The E. affinis complex (Atlantic clade, aka E. carolleeae) draft genome served as the reference genome (Eyun et al., 2017). Automated gene annotation of this genome was conducted at the Baylor College of Medicine Human Genome Sequencing Center within the i5K pilot project (using Maker 2.2, for details see Eyun et al., 2017), resulting in 29,783 gene models. To improve the automated gene annotation, we used the Cufflinks Tuxedo protocol (Trapnell et al., 2012). We employed a genome-guided transcriptome assembly protocol using the E. affinis complex draft genome sequence as a reference. We first mapped the RNA-seq reads of each of the 22 samples to the E. affinis complex reference genome via TopHat using default parameters. Then, we provided the mapped reads as input into Cufflinks to obtain a separate transcript assembly for each of the 22 samples. Finally, we merged all these assembly files (using the Cuffmerge utility within default options ) with automated gene annotation to create a single gene annotation file. We used this improved merged gene annotation file as input into RSEM to (1) build reference transcript sequences using theprepare-reference script (assembled reference transcriptome and gene annotation in GTF format are deposited at the BCO-DMO data system) and (2) align RNA-seq reads to the reference transcripts and estimate gene and transcript abundances (using rsem-calculate expression ). In this study, the term "gene" refers to the set of transcripts that merged into a single locus when we combined transcripts obtained by Cufflinks (22 transcript assemblies) with automated gene annotation obtained using Maker 2.2.

To map RNA-seq reads to the E. affinis complex genome we employed Bowtie, resulting in 16-30 million mapped paired-end reads with a 63-75\% mapping rate (Figure S2 ). In order to verify the annotation of $\mathrm{DE}$ genes, we also performed manual annotation of theE. affinis complex genome (using the Web Apollo platform on the i5k Workspace, https://i5k.nal.usda.gov/) for several thousand genes, including gene families of interest (e.g. ion transporters, CYPs, HSPs, hormones, cuticle proteins, metabolic enzymes, opsins, chemoreceptors). In many cases, multiple paralogs were identified within the genome assembly, which was based on the sequence of a single inbred line. To determine paralog and clade identity of our candidate genes, we constructed phylogenies for the candidate gene families across the Arthropoda, following our prior study Eyun et al. (2017) and using paralog nomenclature consistent with Stern \& Lee (2020).

\subsubsection{Filtering, normalization, and estimation of dispersion}

Structural gene annotation, generated by merging transcriptomes of 22 RNA samples, resulted in 37,827 putative genes. To increase the power to detect differential expression, genes with less than one count-per million $(\mathrm{CPM})$ in at least two samples were filtered out $(\mathrm{n}=17,271)$, as were trnascripts with best blastx match to bacteria $(\mathrm{n}=3)$, and transcripts without blastx hits $(\mathrm{n}=3,189)$. These filtering steps left 14,082 putative genes for the differential gene expression analysis, all of which mapped to the E. affinis genome 
assembly. Subsequently, we performed normalization on 14,082 genes, using the Trimmed Mean of M values method (Robinson \& Oshlack, 2010), available in Bioconductor's edgeR package in the software package R (Chen et al., 2018; Robinson, McCarthy, \& Smyth, 2010) (Figures S3cand S3d).

\subsubsection{Generalized linear model for differential expression analysis}

To identify significant differences in gene expression between saline and freshwater inbred lines (Goal 1) and between salinities ( 0 and 15 PSU) (Goal 2), we performed statistical analyses using a generalized linear model (GLM). To detect DE genes, we applied a negative binomial generalized linear model that accommodated the complex designs of the common-garden experiments. For this purpose, we again employed Bioconductor's edge $R$ package in $\mathrm{R}$ (Chen et al., 2018). In order to accurately estimate gene-wise dispersion, crucial for reliable detection of DE genes (Chen et al., 2018; Robinson \& Smyth, 2007), we used the function glmQLFit with option robust $=$ TRUE. To conduct the test for each genotype (inbred line) and salinity combination, we modeled the read counts as the result of the fixed effects of genotype (inbred line effect), salinity ( 0 and 15 PSU), batch, and genotype-by-salinity interactions. To account for multiple hypothesis testing, we adjusted p-values using the Benjamini and Hochberg method (Benjamini \& Hochberg, 1995) with an FDR threshold of 0.05 .

\subsubsection{Gene ontology enrichment analysis}

To obtain gene ontology (GO) terms (Goal 3) we first performedblastx against NCBI's non-redundant and Swiss-Prot protein databases (Bairoch \& Apweiler, 2000; The UniProt Consortium, 2017). Next, we combined the blast results from NCBI NR and Swiss-Prot and conducted functional annotation to obtain all relevant information for significant matches, including descriptions of protein functions and associated GO terms (Figure S1). For this purpose, we followed a protocol developed by De Wit et al. (2012).

To determine gene categories enriched in evolutionary and plastic transcriptomic responses to salinity change, we performed a functional gene enrichment analysis of DE genes by conducting Fisher's exact test using the topGO elim algorithm (Alexa \& Rahnenfuhrer, 2018). To that end, we used summary statistics $\left(\log _{2} \mathrm{FC}\right.$ and p-values) obtained from the differential gene expression analysis employing GLM (see Section 2.4.2). We conducted GO enrichment analysis for DE genes from Experiment 1, because of greater replication than Experiment 2. To gain greater statistical power, we conducted separate GO analyses for up- and downregulated DE genes, using the summary statistics ( $\log _{2} \mathrm{FC}$ and p-values) obtained from the differential gene expression analysis. Such a strategy is more efficient at finding significant GO processes (Hong et al., 2014). To visualize the results for enriched GO terms, we use the R package GOPlot (Zhong et al., 2004).

\subsubsection{Correlation between evolutionary and plastic changes in gene expression}

To determine whether the direction of acclimatory and evolutionary shifts in genome-wide gene expression were concordant (Goal 4), we calculated correlation coefficients between them. To this end, we calculated Pearson's correlation coefficients between acclimatory shifts (0 PSU vs. 15 PSU within the same inbred line) and evolutionary responses (FW vs. SW inbred lines at the same salinity) in gene expression. We also focused on iono/osmoregulatory genes, given that ionic regulatory function comprised our largest GO category (see Results). To estimate correlation coefficients, we used the log-fold change $\left(\log _{2} \mathrm{FC}\right)$ in gene expression obtained using a generalized liner model (see Section 2.4.2).

To determine whether plasticity in gene expression response had evolved (Goal 5), we compared the direction and magnitude of acclimation response in gene expression between ancestral saline (SW) and derived freshwater (FW) inbred lines. For this purpose, we calculated correlation coefficients between plastic responses (0 PSU/15 PSU) of the SW versus FW inbred lines.

\section{RESULTS}

3.1 Contrasts between evolutionary versus acclimatory responses in genome-wide patterns of gene expression 
Our genome-wide expression analysis of 14,082 putative genes revealed both (1) striking evolutionary differences in gene expression between the saline (SW) versus freshwater (FW) inbred lines (Goal 1), as well as (2) plastic differences in gene expression between saline (15 PSU) versus freshwater conditions (0 PSU) for each line (Goal 2). Patterns of gene expression, evident in multi-dimensional scaling plots (MDS), showed clear separation between saline and freshwater inbred lines, and to a lesser degree between saline (15 PSU) and freshwater (0 PSU) conditions (Figure 2 ).

Overall, evolutionary shifts from saline to freshwater habitats induced far greater changes in gene expression than acclimatory responses, in terms of magnitude of change and numbers of differentially-expressed (DE) genes (Figures 3 and 4 vs. 5 andS6 ; Supplementary Tables 2-5 ). Specifically, approximately 19-28\% of the 14,082 genes were differentially expressed between the SW and FW inbred lines (FDR < 0.05) at 0 PSU or 15 PSU (Figure 3 ), indicating relatively large evolutionary shifts in gene expression between the saline and freshwater populations (Section 3.2, below). In contrast, only $1-4 \%$ genes showed differential expression between the low (0 PSU) and higher (15 PSU) salinity treatments for each inbred line (FDR < 0.05 ,Figure 5 ), indicating relatively weak acclimatory (plastic) responses to salinity (Section 3.3, below). Likewise, far more GO terms were associated with evolutionary shifts between saline and freshwater lines than for acclimatory changes between 0 and 15 PSU (Supplementary Figures S11-S14 ) (Section 3.4).

Intriguingly, many key ion regulatory genes showed both significant evolutionary and acclimatory shifts in gene expression (Figures3 and 5 ; Tables 1-4) (Sections 3.2 and 3.3 below). For a few key ion regulatory genes, such as $N H A-7, N K A$ a -5 , and $N K C C-1$, correlated responses were quite evident between evolutionary and plastic shifts in showing similar direction and magnitude in gene expression (Section 3.5, below). These concordant acclimatory and evolutionary patterns of expression for key ion transporter genes might have been important in facilitating invasions into freshwater habitats (see Discussion, Section 4.3).

3.2 Evolutionary shifts in genome-wide gene expression between saline and freshwater inbred lines

To determine evolutionary shifts in gene expression associated with saline to freshwater invasions (Goal 1), we compared patterns of gene expression between the ancestral saline (SW) and derived freshwater (FW) inbred lines under common-garden conditions (at 0 and 15 PSU). Major categories of DE genes between saline and freshwater inbred lines included those involved in ion transport, sugar and amino acid transport, gene regulation (transcription, translation), neuronal function, metabolism, and energy production (Supplementary Tables $\mathbf{2}$ and $\mathbf{3}$ ). Interestingly, the top DE genes between FWvs. SW inbred lines were shared under freshwater (0 PSU) and saline (15 PSU) conditions (Supplementary Table 6 ).

Of the DE genes between saline and freshwater inbred lines, the largest category from our gene ontology analysis consisted of genes regarded as critical for ionic and osmotic regulation (see Section 3.4, below) (Tables 1 and $2 ;$ Figures S4 and S5 ). Most notable were the divergent patterns of gene expression between FW and SW lines displayed by different paralogs of key ion transporters, including paralogs of the $\mathrm{Na}^{+} / \mathrm{H}^{+}$antiporter $(\mathrm{NHA}), \mathrm{Na}^{+} / \mathrm{K}^{+}$-ATPase (NKA), ammonium transporter $(\mathrm{AMT}), \mathrm{Na}^{+} / \mathrm{H}^{+}$-exchanger $(\mathrm{NHE})$, and $\mathrm{Na}^{+}, \mathrm{K}^{+}, 2 \mathrm{Cl}^{-}$cotransporter $(\mathrm{NKCC})$, as well as paralogs of alpha-carbonic anhydrase $(a-C A)$. A most intriguing result was that the different paralogs of the ion transporters often showed divergent patterns of gene expression from one another at a given salinity (Tables 1 and 2 ; see Discussion Section 4.2).

Overall, many of the ion transporter genes that showed evolutionary shifts in expression between the freshwater and saline inbred lines were shared at both the freshwater (0 PSU) and saline (15 PSU) common-garden

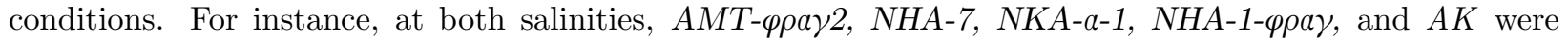
generally upregulated in the freshwater inbred lines relative to the saline lines (Tables 1and $\mathbf{2}$ ). On the other hand, many ion regulatory-related genes, such as $N a \varsigma \eta$, $a-{ }^{\prime \prime} A$ (paralogs $12,8,7,14$ ), NKA- $\beta$ (paralogs 3 , 2, 4), Rh-2, NBC, NKCC (paralogs 1, 4, frag), were generally upregulated in the saline inbred lines, relative to the freshwater inbred lines, at both salinities (Tables $\mathbf{1}$ and $\mathbf{2}$ ).

A conspicuous pattern was that alpha - carbonic anhydraseparalog 9 ( $a$-" $A-9)$ was upregulated in the freshwater inbred lines (relative to their saline ancestral lines) only under freshwater conditions (Table 1, Figure 
S4 ). This result diverged from the downregulation of several other $a-{ }^{-1} A$ paralogs $(12,8,7,14)$ in the freshwater lines relative to the saline lines, suggesting divergent function of the $a-{ }^{-1} A-9$ paralog. Interestingly, we found evolutionary increases in expression of the key sodium transporter $\mathrm{Na}^{+} / \mathrm{H}^{+}$-antiporter $(\mathrm{NHA})$ paralog 7 and paralog 1 (fragment) in the freshwater inbred lines relative to their saline ancestral lines (Table 1; Figure S4 ) (see Discussion, Section 4.2). In terms of powering ion uptake from the environment, we did find the upregulation of $\mathrm{Na}^{+} / \mathrm{K}^{+}$-ATPase subunit alpha, paralog $1(N K A-a-1)$ in the freshwater inbred lines, relative to the saline lines, at both salinities (Tables $\mathbf{1}$ and 2, Figures S4 and S5 ). Arginine kinase (AK ), an enzyme critical for the maintenance of ATP, was also upregulated in the freshwater inbred lines at both salinities (Tables 1 and2, Figure S4 ).

\subsection{Acclimatory changes in genome-wide gene expression in response to salinity}

Comparisons of gene expression levels of the same genotype (inbred line) under contrasting salinity conditions (0 vs. 15 PSU) reveal gene expression changes due to acclimation (phenotypic plasticity) in response to salinity (Goal 2). We found $99 \mathrm{DE}$ genes between salinity conditions in both freshwater inbred lines (Figures 5 andS6 ; Supplementary Table 4 ) and 197 genes that were DE between salinity conditions in both saline lines (Figures 5 andS6 ; Supplementary Table 5 ). Out of these DE genes, 51 genes were differentially expressed between 0 and 15 PSU in both saline and freshwater inbred lines, in both experiments (Supplementary Table 7 ).

In terms of ion regulatory genes, acclimatory shifts in gene expression between 0 vs . 15 PSU tended to show concordant patterns for the saline and freshwater lines (Figure 5 ; Figures S7 andS8; Tables 3 and 4 ). For instance, both the FW and SW inbred lines showed increases in expression at 0 PSU for paralogs and subunits of the ion transporters $\mathrm{Na}^{+} / \mathrm{K}^{+}$-ATPase ( $\mathrm{NKA}$ ), $\mathrm{Na}^{+}, \mathrm{K}^{+}, 2 \mathrm{Cl}^{-}$cotransporter ( $\mathrm{NKCC}$ ), ammonia transporter ( $\mathrm{AMT}$ ), $\mathrm{Na}^{+} / \mathrm{H}^{+}$exchanger $(\mathrm{NHE})$, and $\mathrm{Na}^{+}, \mathrm{HCO}_{3}{ }^{-}$cotransporter $(\mathrm{NBC}$ ) (Tables 3 and 4 ). These genes might represent shared mechanisms of ion uptake in both saline and freshwater populations in response to low salinity conditions. In contrast, the ion transporter genes that were upregulated at $15 \mathrm{PSU}$ (and downregulated at 0 PSU) in both the SW and FW inbred lines included $N K C C$ paralogs, some $\mathrm{Cl}^{-} / \mathrm{HCO}_{3}{ }^{-}$exchangers (i.e., $\mathrm{AE}, \mathrm{NDCBE}$ ), and $\mathrm{NHE}-\mathrm{X}-d$ (Tables 3 and 4 ). These ion transporters might be involved in ion excretion under saline (15 PSU) conditions.

\subsection{Gene ontology enrichment of genes showing evolutionary or acclimatory shifts in expression}

We explored functional categories of genes that showed evolutionary and acclimatory shifts in expression associated with salinity change (Goal 3). In terms of evolutionary response, of the 1716 upregulated genes in the freshwater relative to saline lines at 0 PSU (for Experiment 1) (Supplementary Table 2 ), we found 11 upregulated biological processes $(\mathrm{p}<0.005)$ (Figure S11a ;Supplementary Table 8 ). The upregulated biological process showing the largest evolutionary increase in the freshwater line, in terms of number of genes, was 'inorganic cation transmembrane transport' (40 significant genes out of 225 genes annotated to GO:0098662) (Supplementary Table 8 ; Figure S11 ). Other top upregulated biological processes (BP) included 'sensory perception of smell,' 'dopamine transport,' 'angiotensin maturation microtubule nucleation ,' and various catabolic processes (Figure S11 ). Of the 2087 downregulated genes in FW relative to SW inbred lines at 0 PSU (Supplementary Table 2 ), we found 11 biological processes (Figure S11b ; Supplementary Table $\mathbf{9}$ ). The largest downregulated biological process was 'epidermis development' (30 genes), while other significant GO terms were mostly related to amino acid transport (Supplementary Table 9 ).

When we examined enriched biological processes for the evolutionary response (FW2 vs. SW1) under saline conditions (15 PSU), we observed fewer significant GO terms and fewer significantly up- or down-regulated genes within the GO terms than at 0 PSU (Supplementary Tables 10 and 11 ). Here, we found 5 overrepresented biological processes within the set of 1768 upregulated genes and 11 overrepresented biological processes in the set of 2152 downregulated genes $(\mathrm{p}<0.005)$ (Figure S12 ). 'angiotensin maturation' was the top enriched upregulated GO term, while 'eye-antennal disc morphogenesis' was the top downregulated GO term (Supplementary Tables 11 and12 ). 
When examining acclimation (0 PSU vs. 15 PSU) in the SW1 and FW2 inbred lines, the gene sets that we used to infer up- and downregulated biological processes contained only $\sim 200$ significant DE genes. Therefore, significant GO terms included only a few genes, $2-5$ in both FW2 and SW1 inbred lines (Supplementary Tables 12 -15, Figures S13 and S14), far fewer than what we observed for evolutionary shifts (Supplementary Table 10 ).

\subsection{Correlated evolutionary and acclimatory changes in gene expression}

We determined whether the magnitude and direction of plasticity in gene expression were correlated with evolutionary responses, indicating shared mechanisms of acclimation and adaptation and the presence of an acclimatory response that could be favored by selection during invasions (Goal 4). In our genome-wide comparisons, we found weak but highly significant correlations between evolutionary (FW vs. SW inbred lines) and acclimatory (0 PSU vs. 15 PSU) shifts in gene expression (Figures $\mathbf{6 a}, \mathbf{6 b}$ and $\mathbf{S 9}, \mathbf{a}$ andb ). For instance, we found weak positive correlations between evolutionary shifts in gene expression at 15 PSU and acclimation response in the saline inbred lines (Figures 6a and6b, $\mathrm{r}=0.14$ for SW1 and $\mathrm{r}=0.08$ for SW2). While statistically significant, these correlation coefficients were too low to indicate a meaningful association between adaptive (evolutionary) and acclimatory (plastic) genome-wide responses in gene expression (see Discussion, Section 4.3).

In contrast to the weak genome-wide correlations (previous paragraph), key ion transporters displayed strong positive correlations between evolutionary and plastic changes in gene expression (Figures 6c, 6d and S9, c and $\mathbf{d}$ ). That is, focusing on expression patterns of 30 iono/osmoregulatory genes, we found correlated changes (same direction and similar magnitude) between plastic and evolutionary responses. For instance, we observed strong and significant positive correlations between evolutionary shifts in gene expression of $\mathrm{FW} / \mathrm{SW}$ inbred lines under saline conditions and plastic responses in the saline inbred lines (Figure 6c $, \mathrm{r}=0.78$; Figure 6d , $\mathrm{r}=0.58)$, particularly for the ion transporter genes $N H A-7, N H A-5, N K A-a-1$, NKA- $a-5$, and NKCC-2 (Figures 6c and6d ).

\subsection{Evolution of plasticity between saline and freshwater inbred lines}

We examined whether plasticity in gene expression has evolved following freshwater invasions (Goal 5). We found substantial reductions in genome-wide acclimatory response in gene expression (at 0 vs . 15 $\mathrm{PSU}$ ) in the freshwater (FW) lines, relative to the ancestral saline (SW) lines (Figure 7 ). Specifically, the highly correlated plastic response to salinity change between the SW and FW inbred lines exhibited a regression slope $<1(\mathrm{r}=0.48-0.5)$, indicating an overall reduction in plasticity in the freshwater lines (Figures $\mathbf{7 a}$ and $\mathbf{7 b}$ ). Likewise, for individual ion regulatory genes, the freshwater lines generally showed lower plasticity (lower $\log _{2}$ fold-change) in expression relative to the saline inbred lines, particularly for NHA-7, NKA-a-5, NK $K^{\mathrm{ck}}-2, N H A-5$, and $C A-9$ (Tables 3 and 4; Figures $\mathbf{7 c}$ and $\mathbf{7 d}$ ). These results were consistent with predictions that canalization would evolve over a long period of time following invasions into an extraordinarily stressful environment (see Discussion, Section 4.4).

\section{Discussion}

\subsection{Contrasts between evolutionary versus acclimatory changes in gene expression}

Our comprehensive genome-wide analyses of gene expression revealed both evolutionary (Goal 1) and acclimatory (Goal 2) changes in gene expression associated with changes in salinity. In response to salinity change, evolutionary shifts in gene expression were far greater than acclimatory shifts, in terms of both magnitude of expression and number of DE genes (Figures 3-5, Figure S6 ; Tables 1-4 ). The concordant gene expression patterns for acclimatory and evolutionary responses to salinity for key ion transporter genes (such as NHA-7, NKA-a-5 ) suggest that some of the ion transporters are involved in both acclimatory and evolutionary responses (Goals 3,4). Acclimatory responses of these critical ion transporter genes might in fact facilitate rapid phenotypic adaptation by exposing novel phenotypes (e.g. novel expression levels) to the action of natural selection during freshwater invasions (see Section 4.3, below). Interestingly, we discovered that the acclimatory responses in gene expression, both genome-wide and at key ion transporter 
genes, evolved toward canalization during the transition from saline to freshwater habitats (Goal 5; Section 4.4, below).

\subsection{Evolutionary shifts in gene expression following freshwater invasions}

The changes in genome-wide patterns of gene expression between the saline and freshwater inbred lines (reared under common-garden conditions) reflect evolutionary shifts resulting from the invasion of the Great Lakes from the St. Lawrence estuary following the opening the St. Lawrence seaway, around 1959 (Anderson \& Clayton, 1959; Engel, 1962). Thus, much of the evolutionary shifts in gene expression we found likely resulted from natural selection acting in response to drastic changes in salinity, from the saline St. Lawrence estuary and salt marshes (5-40 PSU) to the freshwater Great Lakes (0 PSU, $~ 300 \mu \mathrm{S} / \mathrm{cm}$ conductivity) around 60 years ago (Lee, 1999; Winkler et al., 2008).

In our investigation, we were particularly interested in evolutionary shifts in gene expression, more so than on acclimatory changes. The genes that show evolutionary shifts in expression would more likely underlie the traits undergoing natural selection and, consequently, contribute to freshwater adaptation. Several other studies have examined differences in gene expression among different species or populations of crustaceans (e.g., Rahi et al. 2019; Moshtaghi et al. 2017). However, their experiments were not conducted under common-garden conditions, such that evolutionary versus acclimatory differences in expression are not distinguishable. Moreover, these studies do not account for differences in expression among the multiple ion transporter paralogs in the genome. Thus, their results are difficult to interpret and compare to this study. One study on copepods, using the tidepool Tigriopus californicus, did compare different populations (Northern vs . Southern) using a common-garden approach across a range of salinities (DeBiasse, Kawji, \& Kelly, 2017). However, this study did not examine populations from very different salinity habitats (but both from saline tidepools), such that evolutionary contrasts would be less apparent. Also, the study measured responses to higher salinities $(15,35,60 \mathrm{PSU})$, where osmolyte production becomes important, and was not designed to examine freshwater adaptation.

In terms of the key physiological properties that would evolve during the transition from saline to freshwater habitats, the evolution of body fluid regulation is often necessary to maintain elevated hemolymph osmolality in extremely dilute habitats (Lee et al., 2012). To achieve and maintain adequate ionic composition of body fluids, selection during freshwater invasions might act on (1) increasing rates of ion uptake (Towle \& Weihrauch 2001, Charmantier et al. 2009, Lee et al. 2011, McNamara \& Faria 2012) and/or (2) decreasing ionic losses (such as through reduced integument permeability) (Hosfeld 1999). The former mechanism would involve the action of multiple ion transporters and enzymes working in concert to take up precious ions from the dilute environment (see Figure 8 ). In the copepodE. affinis complex, expression of ion transporters VHA and NKA was found localized in the "Crusalis organs" within the swimming legs, where ion uptake is likely to occur (Gerber et al., 2016; Johnson et al., 2014).

Our findings were consistent with the importance of ion transporters as targets of selection during the evolutionary transition from ancestral saline to freshwater invading populations. For instance, 'inorganic cation transmembrane transport' (GO:0098662) formed the largest biological process showing evolutionary shifts toward increased expression (upregulation) in the freshwater line (Supplementary Table 8 ; Figure S11 ). Many of the genes that showed evolutionary changes in gene expression included multiple paralogs of key ion transporter genes, particularly $N a^{+} / H^{+}$antiporter $(N H A)$, alpha-carbonic anhydrase (a-'A ), and $N a^{+} / K^{+}$ATPase (NKA). Interestingly, the different paralogs of ion transporters displayed divergent patterns of gene expression, suggesting possibly divergence in function among the paralogs, emergence of compensatory functions among them, and/or nuanced transcriptional regulation of paralogous genes with similar functions.

When we examined in detail the evolutionary shifts in gene expression across salinities for ion transporters, the patterns were consistent with hypothesized models of ion uptake from low salinity habitats (seeFigure 8 ) (Charmantier et al., 2009; Lee, 2016; Lee et al., 2011; McNamara \& Faria, 2012). In support of Model 1 (Figure 8a ), evolutionary shifts of certain $N H A$ paralogs suggested that they might serve as the $\mathrm{Na}^{+}$ transporters cooperating with $V H A$ to take up $\mathrm{Na}^{+}$from dilute media in freshwater environments. NHA 
paralogs 7 and 1 (gene fragment) showed evolutionary increases in expression in the freshwater inbred lines across salinities (0 PSU and 15 PSU), relative to their saline ancestral lines (Tables 1 and 2 ; Figure S4and S5 ). Moreover, $\mathrm{NHA}^{-7}$ was a conspicuous outlier in showing a strong significant correlation between acclimatory and evolutionary responses to salinity (Figures 6 and S9). This result suggests that NHA-7 is involved in both acclimatory and adaptive responses, and that its plastic response might potentially play an important role in rapid evolution during freshwater invasions (see Section 4.3, below). Additionally, in our prior study, multiple paralogs of $N H A$ showed significant signatures of selection associated with the transition from saline to freshwater habitats (Stern \& Lee, 2020). Altogether, our results strongly suggest that NHAparalogs serve as potentially important evolutionary targets during saline to freshwater invasions and likely contribute to freshwater adaptation.

While our results suggest a cooperative function between $N H A$ and $V H A$, we know nothing about the potentially divergent functions of the eight $N H A$ paralogs within the E. affinis complex genome. Of the $N H A$ paralogs of the E. affnins complex, the presence of $N H A$ paralogs showing either up- or downregulation in the freshwater lines suggest divergent or compensatory functions among them (Tables $\mathbf{1}$ and $\mathbf{2}$ ). Prior studies on insects (mosquito larvae and Drosophila melanogaster ) have found functions for NHA paralogs related to $\mathrm{Na}^{+}, \mathrm{Li}^{+}$, or $\mathrm{Cl}^{-}$transport (Chintapalli et al., 2015; Day et al., 2008; Harvey et al., 2010; Xiang et al., 2012). Functional studies, such as heterologous gene expression experiments (Piermarini, Choi, \& Boron, 2007; Piermarini et al., 2010, Piermarini et al., 2013; Piermarini et al., 2009), are needed to discover the stoichiometry of ion transport for each NHA paralog.

The secondary ion transporter that cooperates with VHA to take up $\mathrm{Na}^{+}$and/or other cations from the environment has been unclear and controversial. Based on stoichiometry, Wieczorek and colleagues hypothesized that an electrogenic antiporter that exchanges cations with $\mathrm{H}^{+}$must be cooperating with VHA (Beyenbach \& Wieczorek, 2006; Wieczorek et al., 1991). This unknown $\mathrm{Na}^{+}$transporter that cooperates with VHA, later dubbed the "Wieczorek exchanger," has been hypothesized to be alternatively $\mathrm{Na}^{+}$channel (Nach), $\mathrm{Na}^{+} / \mathrm{H}^{+}$exchanger (NHE), or $\mathrm{Na}^{+} / \mathrm{H}^{+}$antiporter (NHA) (Charmantier et al., 2009; Day et al., 2008; Dymowska et al., 2015; McNamara \& Faria, 2012; Xiang et al., 2012). The $\mathrm{Na}^{+} / \mathrm{H}^{+}$antiporter gene family (NHA or $S L C 9 B$, Figure 8a , white) was first discovered in animals only in 2007, and its functions are still in the early stages of discovery (Brett, Donowitz, \& Rao, 2005; Day et al., 2008; Rheault et al., 2007; Xiang et al., 2012). While NHA does seem to be critical for ion homeostasis and response to salt stress in insects, functional studies in animals have yielded divergent results, suggesting that functions might vary among NHA paralogs, cell types, tissues, and taxa (Chintapalli et al., 2015; Day et al., 2008; Xiang et al., 2012).

The ion transporters $\mathrm{Na}^{+}$Channel (Nach ) and NHE are far less likely to serve as the "Wieczorek exchanger" that cooperates with $V H A$ to perform $\mathrm{Na}^{+}$uptake from freshwater habitats for the E. affinis complex. Nachexhibited an evolutionary shift toward reduced expression in the freshwater lines (Tables 1 and $\mathbf{2}$ ). The upregulation of both NHE and $R h$ protein in the saline lines at 0 PSU was consistent with the saline populations, but not the freshwater populations, using the mechanism of Model 2 for ion uptake under low salinity conditions (Figure 8b ; Table $\mathbf{1}$ ). However, additional functional studies are needed to determine the consequences of evolutionary shifts in expression for these ion transporters.

The strong upregulation of a single paralog of alpha-carbonic anhydrase $(\alpha-C A-9)$ in the freshwater lines at 0 PSU was consistent with both models of ion uptake under freshwater conditions (Table 1 ; Figure 8 ). Carbonic anhydrase $(\mathrm{CA})$ is an enzyme that reversibly catalyzes the chemical reaction $\mathrm{H}_{2} \mathrm{O}+\mathrm{CO}_{2}=\mathrm{H}^{+}+$ $\mathrm{HCO}_{3}{ }^{-}$. The resulting protons $\mathrm{H}^{+}$are then supplied to VHA, whereas bicarbonate is supplied to $\mathrm{Cl}^{-} / \mathrm{HCO}_{3}{ }^{-}$ exchanger (Anion Exchanger, AE) or some other bicarbonate exchanger (e.g. NDCBE). Thus, this enzyme is likely important for the functioning of ion uptake by both NHA and NHE. The high number of $a-$ " $A$ paralogs (at least 14) in the E. affinis complex genome make it challenging to dissect their functions. In contrast to alpha class carbonic anhydrase paralog 9, five other $a$-"A paralogs showed evolutionary declines in expression in the freshwater lines (and increases in the saline lines) (Tables $\mathbf{1}$ and $\mathbf{2}$ ). Given the various potential functions of carbonic anhydrase (e.g. ion uptake, acid-base regulation, respiration, excretion), 
different $a$-"Aparalogs might be specialized to serve various roles in different cell types and tissues.

Among $N K A$ paralogs and subunits, $N K A-a-1$ and $N K A-a-5$ showed evolutionary increases in expression in the freshwater lines at 0 and/or 15 PSU (Tables 1 and $\mathbf{2}$ ). In addition, the paralogs NKA- $a-1$ and NKA- $a-5$ also stood out as having correlated acclimatory and evolutionary responses (Figures 6 and S9), suggesting that their acclimatory responses might facilitate evolutionary adaptation to fresh water. In contrast, all other NKA subunits and paralogs that were differentially-expressed showed a reduction in expression in the freshwater lines (and upregulation in the saline lines). The downregulation of most NKA subunits and paralogs was consistent with a prior study that found a reduction in NKA enzyme activity in freshwater populations, relative to their saline ancestors, across salinities (Lee et al., 2011). Enzyme kinetic studies tend to measure overall enzyme activity, rather than distinguish among diverse functions of different paralogs. NKA is an essential ion transporter in all cells and performs many different functions, including ion uptake, excretion, and neuronal signaling. Insufficient attention has been given to the partitioning of functions among different ion transporter paralogs, such that we do not know the extent to which particular NKA paralogs are specialized for ion uptake.

From the perspective of the saline population, several ion transporters showed increased expression in the saline inbred lines at both salinities (0 and 15 PSU) (Tables $\mathbf{1}$ and $\mathbf{2}$ ). These ion transporter related genes included $\mathrm{Na}^{+}$channel(Nach), alpha-carbonic anhydrase $(\alpha-C A)$ paralog 12, Rh protein (a type of ammonium transporter), $\mathrm{Na}^{+} / \mathrm{K}^{+}-\mathrm{ATPase}\left(\mathrm{NKA}-\mathrm{\beta}-3\right.$ ), $\mathrm{Na}^{+}, \mathrm{HCO}_{3}{ }^{-}$cotransporter ( $\mathrm{NBC}$ ), and $\mathrm{Na}^{+}, \mathrm{K}^{+}, 2 \mathrm{Cl}^{-}$cotransporter ( $\mathrm{NKCC}$ ) paralogs. The constitutively elevated expression of these ion transporters in the saline population might be due to the greater need for ion excretion in saline habitats (Henry, Lucu, Onken, \& Weihrauch, 2012; Larsen et al., 2014; Wright \& Wood, 2009). Alternatively, given the high expense of ion uptake under freshwater conditions (e.g. expensive ATPases), other compensating physiological changes might have evolved to reduce the need for high levels of ion transporter activity in freshwater-adapted populations, such as lower integument permeability, to reduce ionic losses. Additional functional studies are required to interpret the physiological causes underlying these evolutionary shifts in gene expression.

\subsection{Correlated acclimatory and evolutionary responses}

Correlations between plastic and evolutionary responses would indicate whether the same mechanisms are involved during acclimation and adaptation to freshwater conditions (Mäkinen, Papakostas, Vøllestad, Leder, \& Primmer, 2015). Additionally, such correlations might suggest that a plastic response could facilitate rapid evolutionary adaptation (see end of section). We were especially interested these correlations for the saline (SW) lines (Figure 6 ) because the ancestral saline population would have been under selection during freshwater invasions.

When examining correlations between acclimatory and evolutionary shifts in gene expression in response to salinity change, certain key ion transporters were notable in showing strong and significant correlations (Figures 6c , 6d , S9-c ,S9-d ; Pearson's $\mathrm{r}=0.39-0.78)$. That is, ion transporter genes showed the same direction and magnitude of gene expression change for acclimation responses between 15 and 0 PSU and evolutionary shifts between the saline and freshwater lines. This pattern was in sharp contrast to the weak positive correlation between acclimatory and evolution responses in genome-wide gene expression, which were significant but very low (Figures 6a , 6b ,S9-a , S9-b; Pearson's r = 0.08-0.14). The ion transporter genes $N H A-7, N K A-a-5$, and NKA- $a-1$ generally showed especially strong significant correlations in acclimatory and evolutionary responses (Figure 6 ; also SupplementaryFigures S9 and S10 ). These ion transporters are implicated in a major model of ion uptake from freshwater environments (see above, Figure 8a ). Some NKCC paralogs also showed significant correlations, showing both up- or downregulation in freshwater conditions or freshwater lines, but their roles in ion uptake or ion excretion are not clear.

The concordant acclimatory and evolutionary responses in gene expression changes for the few key ion transporters (Figures 6c ,6d and S9-c, S9-d ) suggest some interplay between acclimatory and adaptive mechanisms. Following extreme environmental change, a strong acclimatory response (steep reaction 
norm slope) could promote rapid phenotypic evolution and subsequent genetic adaptation (Lande, 2009; Waddington, 1953). A strong beneficial plastic response in novel conditions, such as increased expression of a critical ion transporter in fresh water, could enable a population to survive in the novel habitat. Selection could then act to favor that expressed extreme phenotype, essentially selecting for the more plastic reaction norm. Eventually, plasticity would erode over time, as the beneficial trait in the original environment would no longer be required in the novel environment and might be costly. Thus, this process by which a plastic response becomes genetically encoded would lead to "genetic assimilation" (Lande, 2009; Waddington, 1953) (see next section).

\subsection{Evolution of plasticity following freshwater invasions}

The regulation of gene expression is a fundamental mechanism that controls plasticity of some traits, resulting in acclimatory responses. However, the precise mechanisms underlying gene expression control of plasticity and acclimatory responses are not well understood (Podrabsky \& Somero, 2004; Yampolsky et al., 2014). Acclimatory responses themselves can be heritable phenotypic traits with the potential to evolve. That is, natural selection can act on plasticity itself, leading to the evolution of increased plasticity or canalization (reduced plasticity) (Chevin \& Lande, 2011; Lande, 2009; Lande, 2015).

In our study, the evolution of reduced plasticity (increased canalization) was apparent in the freshwater lines relative to their saline ancestors. The freshwater lines showed reduced magnitude in gene expression in response to salinity, relative to the ancestral saline lines, as indicated by reduced $\log _{2}$ fold-changes and regression line slopes of less than 1 (Figures $\mathbf{7 a}$ and $\mathbf{7 b}$; also see Tables $\mathbf{3}$ and $\mathbf{4}$ ). This reduction in gene expression in the freshwater lines was apparent genome-wide (for 14,000 genes; Figures 7a and $\mathbf{7 b}$ ), as well as for key ion transporters, such as NHA-7, NHA-5, NKA-a-5,and NKCC-2 (Figure 7 ).

These results were consistent with predictions of Lande's model (2009) and Waddington's argument (1953) regarding the reduction of plasticity over long periods of time following the colonization of a novel extreme environment (see Section 4.3). Consistent with Lande's model, the freshwater lines showed a reduced plastic response in gene expression on a genome-wide scale and at key ion transporters, relative to the saline lines (Figure 7 ; Tables 3 vs . 4 ). The current invasion in the Great Lakes is now $\sim 60$ years old $\left({ }^{\sim} 360\right.$ generations), such that the freshwater populations are now likely undergoing the process of canalization (perhaps due to costs of retaining plasticity). Freshwater habitats, while extreme in their deficit of ions, are relatively constant in their ionic composition and would not warrant retaining large plastic responses to salinity change. In contrast, for the ancestral saline population the retention of large plastic responses would be beneficial for their lifestyle in estuaries and salt marshes that experience large daily and seasonal fluctuations in salinity. Large plastic responses at the critical ion transporter genes in the saline population likely provided the genetic substrate upon which natural selection could act, and consequently could have played important roles in facilitating invasions into freshwater environments (Lande, 2009; Stern \& Lee, 2020).

The evolution of reduced plasticity in the freshwater lines found here is inconsistent with the evolution of increased plasticity of $\mathrm{V}$-type $\mathrm{H}^{+}$ATPase activity in the freshwater populations, under freshwater conditions, found in a prior study (Lee et al., 2011). The previous study examined enzyme kinetics of the partially purified ion transporter enzyme, whereas this study examined the expression of individual genes. Gene expression is often correlated with protein expression and activity, but not always. The proton pump V-type ATPase is composed of multiple subunits encoded by 13 different genes, such that many factors could affect its enzyme activity, other than expression of individual genes. Thus, caution should be taken to not equate gene expression with functions of the actual ion transporters. Additional functional studies (e.g. enzyme kinetics of the ion transporters) are needed to determine how ion transporter function and plasticity evolve during the transition from saline to freshwater habitats.

\section{Acknowledgements}

This project was funded by NSF grants OCE-1658517, OCE-1046372 and DEB-1050565 to Carol E. Lee and OCE-1046371 to Joana C. Silva. Marijan Posavi received graduate research fellowships and grants from the 
Department of Integrative Biology, University of Wisconsin. Jamie Hilton, Jane Remfert, and Kristin Lee assisted with conducting the common-garden experiments. Martin Bontrager performed BLAST searches against large databases (NCBI NR and SwissProt) and functional annotation.

\section{Data Accessibility}

Raw sequence data (RNA-seq) has been deposited in the NCBI Sequence Read Archive (SRA) database:

Accession Links

SRS1094630 https://www.ncbi.nlm.nih.gov/biosample/4100887

SRS1098212 https://www.ncbi.nlm.nih.gov/biosample/4100888

SRS1098204 https://www.ncbi.nlm.nih.gov/biosample/4100889

SRS1098225 https://www.ncbi.nlm.nih.gov/biosample/4100890

SRS1098167 https://www.ncbi.nlm.nih.gov/biosample/4100891

SRS1098170 https://www.ncbi.nlm.nih.gov/biosample/4100892

SRS1098223 https://www.ncbi.nlm.nih.gov/biosample/4100893

SRS1094632 https://www.ncbi.nlm.nih.gov/biosample/4100894

SRS1098217 https://www.ncbi.nlm.nih.gov/biosample/4100895

SRS1098259 https://www.ncbi.nlm.nih.gov/biosample/4100896

SRS1098231 https://www.ncbi.nlm.nih.gov/biosample/4100903

SRS1098172 https://www.ncbi.nlm.nih.gov/biosample/4100904

SRS1098166 https://www.ncbi.nlm.nih.gov/biosample/4100905

SRS1098215 https://www.ncbi.nlm.nih.gov/biosample/4100906

SRS1098216 https://www.ncbi.nlm.nih.gov/biosample/4100907

SRS1098203 https://www.ncbi.nlm.nih.gov/biosample/4100908

SRS1098221 https://www.ncbi.nlm.nih.gov/biosample/4100915

SRS1098230 https://www.ncbi.nlm.nih.gov/biosample/4100916

SRS1098218 https://www.ncbi.nlm.nih.gov/biosample/4100917

SRS1098227 https://www.ncbi.nlm.nih.gov/biosample/4100918

SRS1098208 https://www.ncbi.nlm.nih.gov/biosample/4100919

SRS1098209 https://www.ncbi.nlm.nih.gov/biosample/4100920

\section{Author Contributions}

MP and CEL designed the study. MP conducted the experiments, designed the RNA-seq analysis pipeline, conducted data processing and analyses, and made the corresponding figures. CEL supervised the commongarden experiments, helped construct tables and figures, and determined identities of ion transporter genes via manual annotation of theE. affinis complex genome. DG conducted correlation analysis and made corresponding figures. JCS coordinated generation and management of sequencing data and reviewed the manuscript. JBM contributed to data processing and analysis and was responsible for data management and release. CEL, MP, and DG wrote the manuscript.

\section{References}


Alekseev, V., \& Souissi, A. (2011). A new species within theEurytemora affinis complex (Copepoda: Calanoida) from the Atlantic Coast of USA, with observations on eight morphologically different European populations. Zootaxa, 2767, 41-56.

Alexa, A., \& Rahnenfuhrer, J. (2018). topGO: Enrichment Analysis for Gene Ontology. R package version 2.34.0.

Anderson, D. V., \& Clayton, D. (1959). Plankton in Lake Ontario(Physics Res. Note, No. 1). Retrieved from Maple, Ontario: Div. Res., Dept. Lands and Forests

Bairoch, A., \& Apweiler, R. (2000). The SWISS-PROT protein sequence database and its supplement TrEMBL in 2000. Nucleic Acids Research, 28 (1), 45-48.

Benjamini, Y., \& Hochberg, Y. (1995). Controlling the false discovery rate: a practical and powerful approach to multiple testing. Journal of the Royal Statistical Society. Series B (Methodological), 57 (1), 289-300.

Beyenbach, K. W., \& Wieczorek, H. (2006). The V-type $\mathrm{H}^{+}$ATPase: molecular structure and function, physiological roles and regulation. Journal of Experimental Biology, 209 , 577-589.

Bintanja, R. \& Selten, F.M. (2014). Future increases in Arctic precipitation linked to local evaporation and sea-ice retreat.Nature, 509 , 479-483.

Bolger, A. M., Usadel, B., \& Lohse, M. (2014). Trimmomatic: a flexible trimmer for Illumina sequence data. Bioinformatics, 30 (15), 2114-2120. doi:10.1093/bioinformatics/btu170 \%J Bioinformatics

Brett, C. L., Donowitz, M., \& Rao, R. (2005). Evolutionary origins of eukaryotic sodium/proton exchangers. American Journal of Physiology. Cell Physiology, 288 (2), C223-C239.

Bullard, J. H., Purdom, E., Hansen, K. D., \& Dudoit, S. J. B. B. (2010). Evaluation of statistical methods for normalization and differential expression in mRNA-Seq experiments. 11 (1), 94. doi:10.1186/1471-2105$11-94$

Casties, I., Seebens, H., \& Briski, E. (2016). Importance of geographic origin for invasion success: A case study of the North and Baltic Seas versus the Great Lakes-St. Lawrence River region. Ecology and Evolution, $6,8318-8329$.

Charmantier, G., Charmantier-Daures, M., \& Towle, D. (2009). Osmotic and ionic regulation in aquatic arthropods. In D. H. Evans (Ed.), Osmotic and ionic regulation. Cells and animals (pp. 165-230). Boa-CA Raton, FL, New York, NY, Oxford, UK: CRC Press.

Chen, Y., McCarthy, D. J., Ritchie, M., Robinson, M., \& Smyth, G. K. (2018). edgeR: differential expression analysisof digital gene expression data. User's guide .

Chevin, L.-M., \& Lande, R. (2011). Adaptation to marginal habitats by evolution of increased phenotypic plasticity. Journal of Evolutionary Biology, 24 (7), 1462-1476.

Chintapalli, V. R., Kato, A., Henderson, L., Hirata, T., Woods, D. J., Overend, G., . . . Dow, J. A. (2015). Transport proteins NHA1 and NHA2 are essential for survival, but have distinct transport modalities.Proceeding of the National Academy of Sciences USA, 112 (37), 11720-11725.

Cristescu, M. E. A., Hebert, P. D. N., Witt, J. D. S., MacIsaac, H. J., \& Grigorovich, I. A. (2001). An invasion history for Cercopagis pengoi based on mitochondrial gene sequences. Limnology and Oceanography, $46(2), 224-229$.

Day, J. P., Wan, S., Allan, A. K., Kean, L., Davies, S. A., Gray, J. V., \& Dow, J. A. (2008). Identification of two partners from the bacterial Kef exchanger family for the apical plasma membrane V-ATPase of Metazoa.Journal of Cell Science, 121 (Pt 15), 2612-2619. 
DeBiasse, M. B., Y. Kawji, \& M. W. Kelly. (2017). Phenotypic and transcriptomic responses to salinity stress across genetically and geographically divergent Tigriopus californicus populations.Molecular Ecology, 27, 1621-1632.

Dermott, R., Witt, J., Um, Y. M., \& Gonzalez, M. (1998). Distribution of the Ponto-Caspian amphipod Echinogammarus ischnus in the Great Lakes and replacement of native Gammarus fasciatus. Journal of Great Lakes Research, 24 (2), 442-452.

De Wit, P., Pespeni, M. H., Ladner, J. T., Barshis, D. J., Seneca, F., Jaris, H., Therkildsen, N. O., Morikawa, M., \& Palumbi, S. R. (2012). The simple fool's guide to population genomics via RNA-Seq: an introduction to high-throughput sequencing data analysis.Molecular ecology resources , 12 (6), 1058-1067. https://doi.org/10.1111/1755-0998.12003.

Dietz, T. H., Wilcox, S. J., Byrne, R. A., Lynn, J. W., \& Silverman, H. (1996). Osmotic and ionic regulation of North American zebra mussels (Dreissena polymorpha ). American Zoologist, 36 (3), 364-372.

Durack, P.J., Wijffels, S.E. \& Matear, R.J. (2012). Ocean salinities reveal strong global water cycle Intensification during 1950 to 2000.Science, 336 , 455-458.

Dymowska, A. K., Boyle, D., Schultz, A. G., \& Goss, G. G. (2015). The role of acid-sensing ion channels in epithelial Na+ uptake in adult zebrafish (Danio rerio). Journal of Experimenal Biology, 218 , 1244-1251.

Dymowska, A. K., Hwang, P. P., \& Goss, G. G. (2012). Structure and function of ionocytes in the freshwater fish gill. Respiratory Physiology 83 Neurobiology, 184 (3), 282- 292.

Engel, R. A. (1962). Eurytemora affinis, a calanoid copepod new to Lake Erie. Ohio Journal of Science, 62, 252 .

Evans, D. H., \& Clairborne, J. B. (2009). Osmotic and ionic regulation in fishes. In D. H. Evans (Ed.), Osmotic and Ionic Regulation: Cells and Animals (pp. 295-366).

Eyun, S.-I., Soh, H. Y., Posavi, M., Munro, J. B., Hughes, D. S. T., Murali, S. C., . . . Lee, C. E. (2017). Evolutionary History of Chemosensory-Related Gene Families across the Arthropoda.Molecular biology and evolution, 34 (8), 1838-1862. doi:10.1093/molbev/msx147

Fitzpatrick, B. M. (2012). Underappreciated Consequences of Phenotypic Plasticity for Ecological Speciation. International Journal of Ecology.2012 , 12. doi:10.1155/2012/256017

Gelembiuk, G. W., May, G. E., \& Lee, C. E. (2006). Phylogeography and systematics of zebra mussels and related species. Molecular Ecology, 15 , 1033-1050.

Gerber, L., Lee, C. E., Grousset, E., Blondeau-Bidet, E., Boucheker, N. B., Lorin-Nebel, C., . . . Charmantier, G. (2016). The Legs Have It: In situ expression of ion transporters V-Type $\mathrm{H}^{+}$ATPase and $\mathrm{Na}^{+} / \mathrm{K}^{+}$-ATPase in osmoregulating leg organs of the invading copepod Eurytemora affinis .Physiological and Biochemical Zoology, 89 (3), 233-250.

Gulati, R. D., \& Doornekamp, A. (1991). The spring-time abundance and feeding of Eurytemora affinis (Poppe) in Volkerak-Zoommeer, a newly-created freshwater lake system in the Rhine delta (The Netherlands). Aquatic Ecology, 25 (1), 51-60.

Harvey, W. R., Okech, B. A., Linser, P. J., Becnel, J. J., Ahearn, G. A., \& Sterling, K. M. (2010). H ${ }^{+}$ V-ATPase-energized transporters in brush border membrane vesicles from whole larvae ofAedes aegypti . Journal of Insect Physiology, 10 , 1377-1389.

Heinle, D. R., \& Flemer, D. A. (1975). Carbon requirements of a population of the estuarine copepod Eurytemora affinis . Marine Biology, 31 , 235-247.

Henry, R. P. (1996). Multiple roles of carbonic anhydrase in cellular transport and metabolism. Annual Review of Physiology, 58 , 523-538. 
Henry, R. P., Lucu, C., Onken, H., \& Weihrauch, D. (2012). Multiple functions of the crustacean gill: osmotic/ionic regulation, acid-base balance, ammonia excretion and bioaccumulation of toxic metals.Frontiers in Physiology, 3 , 431-463.

Hong, G., Zhang, W., Li, H., Shen, X., \& Guo, Z. (2014). Separate enrichment analysis of pathways for up- and downregulated genes.Journal of the Royal Society, Interface, 11 (92), 20130950-20130950. doi:10.1098/rsif.2013.0950

Ito, Y., Kobayashi, S., Nakamura, N., Miyagi, H., Esaki, M., Hoshijima, K., \& Hirose, S. (2013). Close association of carbonic anhydrase (CA2a and CA15a), $\mathrm{Na}(+) / \mathrm{H}(+)$ exchanger (Nhe3b), and ammonia transporter Rhcg1 in zebrafish ionocytes responsible for $\mathrm{Na}(+)$ uptake. Frontiers in Physiology, 4, 59.

Johnson, K. E., Perreau, L., Charmantier, G., Charmantier-Daures, M., \& Lee, C. E. (2014). Without Gills: Localization of osmoregulatory function in the copepod Eurytemora affinis . Physiological and Biochemical Zoology, 87, 310-324.

Kimmel, D. G., Miller, W. D., \& Roman, M. R. (2006). Regional scale climate forcing of mesozooplankton dynamics in Chesapeake Bay.Estuaries and Coasts, 29 (3), 375-387.

Kondapalli, K. C., Kallay, L. M., Muszelik, M., \& Rao, R. (2012). Unconventional chemiosmotic coupling of NHA2, a mammalian $\mathrm{Na}^{+} / \mathrm{H}^{+}$antiporter, to a plasma membrane $\mathrm{H}^{+}$gradient. Journal of Biological Chemistry, 287 (43), 36239-36250.

Kumai, Y., \& Perry, S. F. (2012). Mechanisms and regulation of $\mathrm{Na}^{+}$uptake by freshwater fish. Respiratory Physiology 83 Neurobiology, 184 (3), 249-256.

Lande, R. (2009). Adaptation to an extraordinary environment by evolution of phenotypic plasticity and genetic assimilation. Journal of Evolutionary Biology, 22 (7), 1435-1446.

Lande, R. (2015). Evolution of phenotypic plasticity in colonizing species. Molecular Ecology, 24, 20382045 .

Larsen, E. H., Deaton, L. E., Onken, H., O’Donnell, M., Grosell, M., Dantzler, W. H., \& Weihrauch, D. (2014). Osmoregulation and Excretion.Comprehensive Physiology, 4 , 405-573.

Lee, C. E. (1999). Rapid and repeated invasions of fresh water by the saltwater copepod Eurytemora affinis . Evolution, 53 , 1423-1434.

Lee, C. E. (2000). Global phylogeography of a cryptic copepod species complex and reproductive isolation between genetically proximate "populations". Evolution, 54 (6), 2014-2027.

Lee, C. E. (2010). Evolution of invasive populations. In D. Simberloff \& M. Rejmánek (Eds.), The Encyclopedia of Biological Invasions(pp. 215-222). Berkeley, Los Angeles, London: University of California Press.

Lee, C. E. (2016). Evolutionary mechanisms of habitat invasions, using the copepod Eurytemora affinis as a model system.Evolutionary Applications, 9 (1), 248-270.

Lee, C. E., \& Bell, M. A. (1999). Causes and consequences of recent freshwater invasions by saltwater animals. Trends in Ecology and Evolution, 14, 284-288.

Lee, C. E., \& Frost, B. W. (2002). Morphological stasis in theEurytemora affinis species complex (Copepoda: Temoridae).Hydrobiologia, 480 , 111-128.

Lee, C. E., \& Gelembiuk, G. W. (2008). Evolutionary origins of invasive populations. Evolutionary Applications, 1 , 427-448.

Lee, C. E., Kiergaard, M., Gelembiuk, G. W., Eads, B. D., \& Posavi, M. (2011). Pumping ions: Rapid parallel evolution of ionic regulation following habitat invasions. Evolution, 65 (8), 2229-2244. 
Lee, C. E., Moss, W. E., Olson, N., Chau, K. F., Chang, Y.-M., \& Johnson, K. E. (2013). Feasting in fresh water: Impacts of food concentration on freshwater tolerance and the evolution of food $\mathrm{x}$ salinity response during the expansion from saline into freshwater habitats. Evolutionary Applications, 6 , 673-689.

Lee, C. E., \& Petersen, C. H. (2002). Genotype-by-environment interaction for salinity tolerance in the freshwater invading copepodEurytemora affinis . Physiological and Biochemical Zoology, 75 (4), 335-344.

Lee, C. E., \& Petersen, C. H. (2003). Effects of developmental acclimation on adult salinity tolerance in the freshwater-invading copepod Eurytemora affinis . Physiological and Biochemical Zoology, 76 (3), 296-301.

Lee, C. E., Posavi, M., \& Charmantier, G. (2012). Rapid evolution of body fluid regulation following independent invasions into freshwater habitats. Journal of Evolutionary Biology, 25 (4), 625-633.

Lee, C. E., Remfert, J. L., \& Chang, Y.-M. (2007). Response to selection and evolvability of invasive populations. Genetica, 129 (2), 179-192.

Lee, C. E., Remfert, J. L., \& Gelembiuk, G. W. (2003). Evolution of Physiological Tolerance and Performance during Freshwater Invasions. Integrative and Comparative Biology , 43 (3), 439-449. doi: 10.1093/icb/43.

Li, B., \& Dewey, C. N. (2011). RSEM: accurate transcript quantification from RNA-seq data with or without a reference genome. BMC Bioinformatics, 12, 323.

Livdāne, L., Putnis, I., Rubene, G., Elferts, D., \& Ikauniece, A. (2016). Baltic herring prey selectively on older copepodites ofEurytemora affinis and Limnocalanus macrurus in the Gulf of Riga. Oceanologia, 58 (1), 46-53.

MacIsaac, H. J., Grigorovich, I. A., \& Ricciardi, A. (2001). Reassessment of species invasions concepts: The Great Lakes basin as a model. Biological Invasions, 3 (4), 405-416.

Mäkinen, H., Papakostas, S., Vøllestad, L. A., Leder, E. H., \& Primmer, C. R. (2015). Plastic and Evolutionary Gene Expression Responses Are Correlated in European Grayling (Thymallus thymallus) Subpopulations Adapted to Different Thermal Environments. Journal of Heredity ,107 (1), 82-89. doi: 10.1093/jhered/esv069

Marsden, J. E., Spidle, A., \& May, B. (1995). Genetic similarity among zebra mussel populations within North Ameria-CA and Europe.Canadian Journal of Fisheries and Aquatic Sciences, 52 (4), 836-847.

Marsden, J. E., Spidle, A. P., \& May, B. (1996). Review of genetic studies of Dreissena spp. American Zoologist, 36 , 259-270.

May, G. E., Gelembiuk, G. W., Panov, V. E., Orlova, M. I., \& Lee, C. E. (2006). Molecular ecology of zebra mussel invasions. Molecular Ecology, 15 , 1021-1031.

McNamara, J. C., \& Faria, S. C. (2012). Evolution of osmoregulatory patterns and gill ion transport mechanisms in the decapod Crustacea: A review. Journal of Comparative Physiology B, 182 (8), 997-1014.

Merilä, J., \& Hendry, A. P. (2014). Climate change, adaptation, and phenotypic plasticity: the problem and the evidence. Evolutionary Applications , 7(1), 1-14.

Morgan, C. A., Cordell, J. R., \& Simenstad, C. A. (1997). Sink or swim? Copepod population maintenance in the Columbia River estuarine turbidity maxima region. Marine Biology, 129 , 309-317.

Moshtaghi, A. Rahi, M. L. Mather, P. B. Hurwood, D. A. (2017). Understanding the Genomic Basis of Adaptive Response to Variable Osmotic Niches in Freshwater Prawns: A Comparative Intraspecific RNASeq Analysis of Macrobrachium australiense. Journal of Heredity , 108 (5), 544-552

Parkhomchuk, D., Borodina, T., Amstislavskiy, V., Banaru, M., Hallen, L., Krobitsch, S., . . . Soldatov, A. (2009). Transcriptome analysis by strand-specific sequencing of complementary DNA. Nucleic Acids Research, 37 (18), e123-e123. doi:10.1093/nar/gkp596 \%J Nucleic Acids Research 
Parks, S. K., Tresguerres, M., \& Goss, G. G. (2008). Theoretical considerations underlying $\mathrm{Na}^{+}$uptake mechanisms in freshwater fishes. Comparative Biochemistry and Physiology. Part C: Toxicology and Pharmacology, 148 (4), 411-418.

Peitsch, A., Kopcke, B., \& Bernat, N. (2000). Long-term Investigation of the distribution of Eurytemora affinis (Calanoida; Copepoda) in the Elbe Estuary. Limnologica, 30 , 175-182.

Podrabsky, J. E., \& Somero, G. N. (2004). Changes in gene expression associated with acclimation to constant temperatures and fluctuating daily temperatures in an annual killifish Austrofundulus limnaeus . Journal of Experimental Biology, 207, 2237-2254.

Posavi, M., Larget, B., Gelembiuk, G. W., \& Lee, C. E. (2014). Testing for beneficial reversal of dominance during salinity shifts in the invasive copepod Eurytemora affinis, and implications for the maintenance of genetic variation. Evolution, 68 (11), 3166-3183.

Primmer, C. R., Leder, E. H., Vøllestad, L. A., Papakostas, S., \& Mäkinen, H. (2015). Plastic and Evolutionary Gene Expression Responses Are Correlated in European Grayling (Thymallus thymallus) Subpopulations Adapted to Different Thermal Environments. Journal of Heredity, 107 (1), 82-89. doi:10.1093/jhered/esv069 \%J Journal of Heredity

Rahi, M. L. Mather, P. B., Ezaz, T., Hurwood, D. A. (2019) The Molecular Basis of Freshwater Adaptation in Prawns: Insights from Comparative Transcriptomics of Three Macrobrachium Species. Genome Biology and Evolution, 11 (4): 1002-1018.

Rewicz, T., Wattier, R., Grabowski, M., Rigaud, T., \& Bacela-Spychalska, K. (2015). Out of the Black Sea: Phylogeography of the Invasive Killer Shrimp Dikerogammarus villosus across Europe.PLoS ONE, 10 (2), e0118121.

Rheault, M. R., Okech, B. A., Keen, S. B., Miller, M. M., Meleshkevitch, E. A., Linser, P. J., . . Harvey, W. R. (2007). Molecular cloning, phylogeny and localization of AgNHA1: the first $\mathrm{Na}^{+} / \mathrm{H}^{+}$antiporter (NHA) from a metazoan, Anopheles gambiae. Journal of Experimental Biology, 210 (Pt 21), 3848-3861.

Robinson, M., \& Oshlack, A. (2010). A scaling normalization method for differential expression analysis of RNA-seq data. Genome Biology, 11 (3), R25. doi:10.1186/gb-2010-11-3-r25

Robinson, M. D., McCarthy, D. J., \& Smyth, G. K. (2010). edgeR: a Bioconductor package for differential expression analysis of digital gene expression data. Bioinformatics, 26 (1), 139-140.

Robinson, M. D., \& Smyth, G. K. (2007). Moderated statistical tests for assessing differences in tag abundance. Bioinformatics, 23 (21), 2881-2887. doi:10.1093/bioinformatics/btm453 \%J Bioinformatics

Shaheen, P. A., Stehlik, L. L., Meise, C. J., Stoner, A. W., Manderson, J. P., \& Adams, D. L. (2001). Feeding behavior of newly settled winter flounder (Pseudopleuronectes americanus) on calanoid copepods. Journal of Experimental Marine Biology and Ecology, 257 (1), 37-51.

Shetlar, R. E., \& Towle, D. W. (1989). Electrogenic sodium-proton exchange in membrane vesicles from crab (Carcinus maenas ) gill.American Journal of Physiology, 257 (4 Pt 2), R924-R931.

Simenstad, C. A., \& Cordell, J. R. (1985). Structural dynamics of epibenthic zooplankton in the Columbia River. Delta. Verh. Internat. Verein. Limnol., 22 , 2173-2182.

Stern, D. B., \& Lee, C. E. (2020). Evolutionary origins of genomic adaptations in an invasive copepod. Nature Ecology and Evolution . https://doi.org/10.1038/s41559-020-1201-y

The UniProt Consortium. (2017). UniProt: the universal protein knowledgebase. Nucleic Acids Research, 45 (D1), D158-D169. doi:10.1093/nar/gkw1099

Towle, D. W., \& Weihrauch, D. (2001). Osmoregulation by gills of euryhaline crabs: Molecular analysis of transporters. American Zoologist, 41 (4), 770-780. 
Trapnell, C., Roberts, A., Goff, L., Pertea, G., Kim, D., Kelley, D. R., . . . Pachter, L. (2012). Differential gene and transcript expression analysis of RNA-seq experiments with TopHat and Cufflinks. Nature Protocols, 7 , 562. doi:10.1038/nprot.2012.016

Viitasalo, M., Flinkman, J., \& Viherluoto, M. (2001). Zooplanktivory in the Baltic Sea: a comparison of prey selectivity by Clupea harengus and Mysis mixta, with reference to prey escape reactions. Marine Ecology Progress Series, 216 191-200.

Waddington, C. H. (1953). Genetic assimilation of an acquired character.Evolution, 7 , 118-126.

Wieczorek, H., Putzenlechne, r. M., Zeiske, W., \& Klein, U. (1991). A vacuolar-type proton pump energizes $\mathrm{K}^{+} / \mathrm{H}^{+}$antiport in an animal plasma membrane. Journal of Biological Chemistry, 266 (23), 15340-15347.

Williamson, M., \& Fitter, A. (1996). The varying success of invaders.Ecology, 77 (6), 1661-1666.

Winkler, G., Dodson, J. J., Bertrand, N., Thivierge, D., \& Vincent, W. F. (2003). Trophic coupling across the St. Lawrence River estuarine transition zone. Marine Ecology Progress Series, 251 , 59-73.

Winkler, G., Dodson, J. J., \& Lee, C. E. (2008). Heterogeneity within the native range: Population genetic analyses of sympatric invasive and noninvasive clades of the freshwater invading copepod Eurytemora affinis . Molecular Ecology, 17 (1), 415-430.

Winkler, G., Sirois, P., Johnson, L. E., \& Dodson, J. J. (2005). Invasion of an estuarine transition zone by Dreissena polymorphaveligers had no detectable effect on zooplankton community structure. Canadian Journal of Fisheries and Aquatic Sciences, 62 , 578-592.

Witt, J. D. S., Hebert, P. D. N., \& Morton, W. B. (1997).Echinogammarus ischnus : Another crustacean invader in the Laurentian Great Lakes basin. Canadian Journal of Fisheries and Aquatic Sciences, 54 (2), 264-268.

Wright, P. A., \& Wood, C. M. (2009). A new paradigm for ammonia excretion in aquatic animals: role of Rhesus (Rh) glycoproteins. Journal of Experimenal Biology, 212 (Pt 15), 2303-2312.

Xiang, M. A., Linser, P. J., Price, D. A., \& Harvey, W. R. (2012). Localization of two $\mathrm{Na}^{+}-$or K$^{+}-\mathrm{H}^{+}$ antiporters, AgNHA1 and AgNHA2, in Anopheles gambiae larval Malpighian tubules and the functional expression of AgNHA2 in yeast. Journal of Insect Physiology, 58 (4), 570-579.

Yampolsky, L. Y., Zeng, E., Lopez, J., Williams, P. J., Dick, K. B., Colbourne, J. K., \& Pfrender, M. E. (2014). Functional genomics of acclimation and adaptation in response to thermal stress inDaphnia . BMC Genomics, 15 , 859 .

Zhong, S. B., Khodursky, A., Dykhuizen, D. E., \& Dean, A. M. (2004). Evolutionary genomics of ecological specialization. Proceedings of the National Academy of Sciences USA, 101 (32), 11719-11724.

\section{Figure Legends}

Figure 1 Design of the common-garden experiment to distinguish between heritable (genetically-based) differences in gene expression between saline and freshwater inbred lines of the E. affiniscomplex and environmentally-induced (plastic) differences in expression at different salinities ( 0 and 15 PSU). The common-garden experiment was conducted in two replicate experiments, Experiment 1 and Experiment 2. SW1 and SW2 = independently-derived saline inbred lines. FW1 and FW2 = independently-derived freshwater inbred lines.

Figure 2 Separation of gene expression patterns between saline and freshwater inbred lines and between saline (15 PSU) and freshwater (0 PSU) conditions. (a , b ) Clustering of saline (red) and freshwater (blue) inbred lines and saline (triangles, 15 PSU) and freshwater (circles, 0 PSU) conditions are shown in twodimensional scaling (MDS) plots for (a ) Experiment 1 (12 samples) and (b ) Experiment 2 (10 samples). Sets of biological replicates $(n=3$, except FW1, where $n=2)$ are well-separated by genotype (inbred line, SW vs. FW) in the first dimension and by salinity conditions (0 PSU vs. 15 PSU) in the second 
dimension. Distances between each pair of inbred line samples (at 0 or 15 PSU) is the root-mean-square deviation (Euclidean distances) for the top 500 genes (showing the largest $\log _{2} \mathrm{FC}$ ). (c , d ) Clustering by Euclidean distances based on regularized log transformation (rlog function in DESseq2 package) of read counts. Distances visualized by heatmaps also show separation of samples by inbred line (SW vs. FW) and salinity conditions (0vs . 15 PSU) in (c) Experiment 1 and (d) Experiment 2. The legend color key indicates the Euclidian distances between the samples. Distances are based on the regularization of the $\log$ fold changes in the count for each sample over an intercept, for each gene; i.e., $\operatorname{rlog}\left(K_{i j}\right)=\log 2\left(q_{i j}\right)=\beta_{i} 0$ $+\beta_{i j}$.

Figure 3 Evolutionary shifts in genome-wide expression between saline and freshwater inbred lines reared under the same salinity conditions (at either 0 or $15 \mathrm{PSU}$ ), for 14,082 genes. Volcano plots show gene expression differences between saline (SW1 and SW2) and freshwater (FW1 and FW2) inbred lines under $(\mathbf{a}, \mathbf{b})$ freshwater (0 PSU) and (c , d ) saline (15 PSU) conditions for replicate Experiments 1 and 2. The horizontal axes indicate the $\log _{2}$ fold-change in gene expression between freshwater and saline inbred lines. The vertical axes indicate the $-\log _{10}$ of FDR adjusted p-value, with higher values indicating greater statistical significance. The horizontal lines within each graph indicate the FDR $=0.05$ threshold. The genes above this horizontal line, showing significant differential expression (FDR $<0.05$ ), are colored according to fold-change direction of expression, with blue dots indicating upregulation in the freshwater inbred lines and red dots representing upregulation in the saline inbred lines. Total number of differentially-expressed genes as well as the number of upregulated genes in FW (blue) and SW (red) inbred lines are indicated in each plot. The greater number of DE genes in Experiment 1 than Experiment 2 is possibly due to lower statistical power in Experiment 2, where the FW1 inbred line had two replicates. Genes potentially involved in ionic regulation are labeled and indicated with yellow dots. Full names of genes are shown in Tables 1 and 2 .

Figure 4 Venn diagrams and heat maps of genes showing evolutionary shifts in expression between saline and freshwater inbred lines, in both Experiments 1 and 2 at (a, c ) 0 PSU and (b, d ) 15 PSU. Venn diagrams show numbers of DE genes in both experiments under (a ) freshwater conditions (0 PSU), with the intersection showing 1152 genes that were DE in both experiments, and (b ) saline conditions (15 PSU), with 1037 genes that were DE in both experiments. Heat maps of genes that were differentially-expressed $($ FDR $<0.05)$ between saline and freshwater inbred lines in both experiments under (c) freshwater (0 PSU, 1152 genes) and (d ) saline (15 PSU, 1037 genes) conditions. On the scale bar, blue indicates lower and red indicates higher levels of gene expression. Both inbred lines and genes were hierarchically clustered by Euclidean distance and average linkage. Dendrogram clustering on the horizontal axis shows inbred line similarity in level and direction of gene expression $(2$ replicates FW1 $=$ light green, 3 replicates of FW2 = dark green, 3 replicates of SW1 $=$ light pink, and 3 replicates of SW2 $=$ dark pink). Clustering according to similarity in pattern of gene expression is shown on the vertical axis, in terms of the $\log _{2}$ of TMM normalized counts per million mapped reads $(\mathrm{CPM})$ for DE genes $(\mathrm{FDR}<0.05)$.

Figure 5 Plastic responses in expression for 14,082 putative genes in the FW and SW inbred lines. Volcano plots show gene expression differences due to acclimation to salinity (0 PSU vs .15 PSU) of (a, b ) freshwater $\left(0 \mathrm{PSU}_{\mathrm{FW}} / 15 \mathrm{PSU}_{\mathrm{FW}}\right)$, and $(\mathbf{c}, \mathbf{d})$ saline $\left(0 \mathrm{PSU}_{\mathrm{SW}} / 15 \mathrm{PSU}_{\mathrm{SW}}\right)$ inbred lines of the E. affinis complex. The horizontal axes indicate the $\log _{2}$ fold-change in gene expression between 0 PSU and 15 PSU conditions for a given inbred line. The vertical axes indicate the $-\log _{10}$ of FDR adjusted p-value, with higher values indicating greater statistical significance. The horizontal lines within each graph indicate the FDR $=0.05$ threshold. The genes above this horizontal line, showing significant differential expression (FDR $<0.05$ ), are colored according to fold-change direction. Blue dots represent genes upregulated under fresh water (0 PSU) and red dots represent genes upregulated under saline (15 PSU) conditions. Total number of DE genes as well as number of upregulated genes under freshwater (blue) and saline (red) conditions are indicated in each plot. Genes potentially involved in ionic regulation are labeled and colored with yellow dots. Full names of genes are shown in Tables 1 and 2.

Figure 6 Correlation between evolutionary shifts (salinevs. freshwater inbred lines at 15 PSU) and plastic responses (between 0 and $15 \mathrm{PSU}$ ) in gene expression in the saline inbred lines of the E. affinis complex 
( $\log _{2} \mathrm{FC}$ of 14,082 genes). The correlation is weak (but significant) genome wide $(\mathrm{r}=0.14$ and 0.08 , upper panels), whereas strong for ion transporter genes $(\mathrm{r}=0.78$ and 0.58 , lower panels). Horizontal axes show the evolutionary responses between freshwater and saline inbred lines under saline (15 PSU) conditions, whereas vertical axes show acclimatory responses (between 0 and 15 PSU) of saline inbred lines. Graphs show results from two replicate experiments, namely (a, c ) Experiment 1, and (b, d ) Experiment 2. Genes potentially involved in ionic regulation, showing high correlation, are labeled and indicated by aquamarine blue filled dots. Lower panels $(\mathbf{c}, \mathbf{d})$ show correlations between evolutionary and plastic responses in the SW inbred lines for 30 putative iono/osmoregulatory genes. The red thick dashed lines represent the linear regression fit curve with $95 \%$ confidence region. $\mathrm{r}=$ Pearson coefficient of correlation, $\mathrm{R}^{2}=$ Coefficient of determination indicating the effect size of correlation. Diagonal black dotted

lines indicate correlation coefficients of $r=1$ (equal magnitude and direction of evolutionary and acclimatory shifts in gene expression) and $\mathrm{r}=-1$ (equal magnitude but opposite direction of evolutionary and acclimatory shifts in gene expression). Full gene names for abbreviations are listed in Tables 1 and 2.

Figure 7 Evolution of genome-wide plasticity in expression from saline to freshwater lines. Correlations between plastic responses in gene expression in the SW versus $\mathrm{FW}$ inbred lines of the copepodE. affinis complex, showing the reduction of plasticity in the freshwater lines both genome-wide (based on $\log _{2} \mathrm{FC}$ of 14,082 genes) and for individual ion transporter genes. Graphs show results from two replicate experiments, namely (a, c ) Experiment 1, showing correlations in gene expression $\left(\log _{2} \mathrm{FC}(0 \mathrm{PSU} / 15 \mathrm{PSU})\right)$ between the SW1 and FW2 inbred lines and (b, d ) Experiment 2, showing correlations in $\log _{2} \mathrm{FC}(0 \mathrm{PSU} / 15 \mathrm{PSU})$ between the SW2 and FW1 inbred lines. Lower values on the axes indicate reduced levels of gene expression under freshwater (0 PSU) relative to saline (15 PSU) conditions for both saline (x-axis) and freshwater (y-axis) inbred lines. The dark blue dashed lines represent the linear regression fit with light purple shading around the dashed lines showing $95 \%$ confidence intervals. The slope of the regression $<1$ indicates that genomewide plasticity is reduced in the freshwater lines, relative to the saline lines. $\mathrm{r}=$ Pearson coefficient of correlation and $\mathrm{R}^{2}=$ Coefficient of determination, indicating the effect size of correlation. Diagonal black dotted lines indicate correlation coefficients of $\mathrm{r}=1$ (equal magnitude and direction of gene expression in SW and FW lines) and $\mathrm{r}=-1$ (equal magnitude but opposite direction of gene expression in SW and FW lines). Genes potentially involved in iono-/osmoregulation that show high correlations are labeled and indicated by yellow filled dots. The lower panel barplots $(\mathbf{c}, \mathbf{d})$ show $\log _{2}$ fold-change in gene expression of iono-/osmoregulatory genes, indicating reduced plastic response in FW relative to SW inbred lines across both experiments. Full gene names for abbreviations are listed in Tables 3 and 4.

Figure 8 Hypothetical models of ion uptake by ionocytes in the E. affinis complex under freshwater conditions. Shown are primary transporters that energize ion transport (VHA, NKA) and hypothetical secondary transporters for sodium uptake (NHA, $\mathrm{Na}^{+}$channel, or NHE). (a) Model 1 (Wieczorek's Model): The proton pump VHA (blue) is localized on the apical membrane of epithelial cells, where it generates a proton gradient by pumping $\mathrm{H}^{+}$ions out of the cell. This transmembrane potential generated by VHA then energizes the uptake of $\mathrm{Na}^{+}$by an unknown secondary transporter, possibly electrogenic NHA or $\mathrm{Na}^{+}$channel.(b) Model 2: Ammonia ( $\left.\mathrm{NH}_{3}\right)$ is transported out of the cell by an ammonia transporter ( $\mathrm{Rh}$ protein). The exported $\mathrm{NH}_{3}$ then reacts with $\mathrm{H}^{+}$to produce $\mathrm{NH}_{4}{ }^{+}$. The lowered external $\mathrm{H}^{+}$concentration then promotes $\mathrm{H}^{+}$export out of the cell and facilitates $\mathrm{Na}^{+}$uptake as a counterion, through NHE activity (Dymowska, Hwang, \& Goss, 2012; Ito et al., 2013; Wright \& Wood, 2009). However, NHE is thought to be less likely to operate at extremely low salinities (Dymowska et al., 2015). In both models, transport of $\mathrm{Na}^{+}$ from the cell to the hemolymph is performed by primary transporter NKA. Cytosolic carbonic anhydrase (CA) performs $\mathrm{CO}_{2}$ hydration, supplying $\mathrm{H}^{+}$and $\mathrm{HCO}_{3}{ }^{-}$to apical or basal ion transporters (Henry, 1996). Additionally, chloride uptake might occur through the $\mathrm{Cl}^{-} / \mathrm{HCO}^{-}$exchanger (anion exchanger, AE) and $\mathrm{Na}^{+} / \mathrm{K}^{+} / 2 \mathrm{Cl}^{-}$cotransporter (NKCC) might also play a role in ion uptake. Alternative models have also been proposed, and not all potentially relevant ion transporters are shown.

\section{Hosted file}

Tables 1 to 4 Marijan Posavi Evolution of genome wide gene expression.docx

available 
at

https://authorea.com/users/337254/articles/462869-rapid-evolution-of-genome-widegene-expression-and-plasticity-during-saline-to-freshwater-invasions-by-the-copepodeurytemora-affinis-species-complex

(a) To remove effects of developmental acclimation to native salinities, juveniles from all four parental fresh and saline inbred lines (FW1, FW2 SW1 and SW2) and sre grally transferred to a common salinity of 5 PSU and then reared at this salinity until mating. Mating was followed by egg production and hatching Mating was
of offspring.

(b) The newly produced offspring were separated from parents and reared at 5 PSU until metamorphosis ( 15 days of age).

(c) When offspring reached metamorphosis, each sample was split across two salinities ( 200 juveniles per salinity, 0 and $15 \mathrm{PSU}$ ).

(d) Juveniles were reared at final salinities (0 PSU and $15 \mathrm{PSU}$ ) for the next $16-18$ days until they became adults. A total of 50 adult copepods ( 25 females and 25 males) were randomly selected from each sample for total RNA extraction.

(e) Three replicates per each inbred line (except FW1) were sequenced by multiplexing 12 samples per two lanes.

\section{Hypotheses testing}

Evolutionary response: Determine $\mathrm{DE}$ genes between FW and SW inbred lines under the same rearing conditions.

Plastic (Acclimatory) response: Determine DE genes within the inbred lines under contrasting conditions $(0$

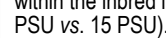

Experiment 1

Experiment 2

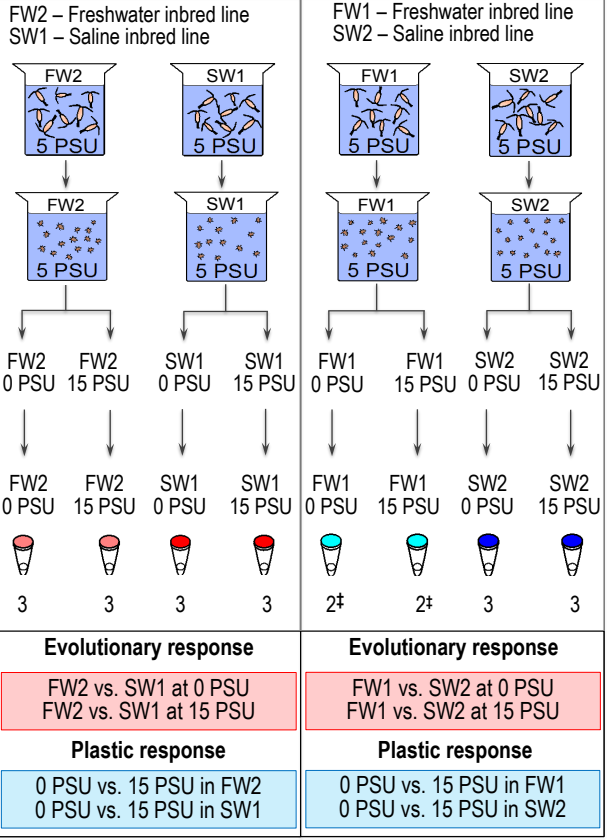

$\ddagger$ One replicate of the FW1 inbred line was excluded because of bacterial infection 
Experiment 1

(a) MDS sample $(n=12)$ clustering based on $\log _{2} \mathrm{FC}$ of top 500 genes

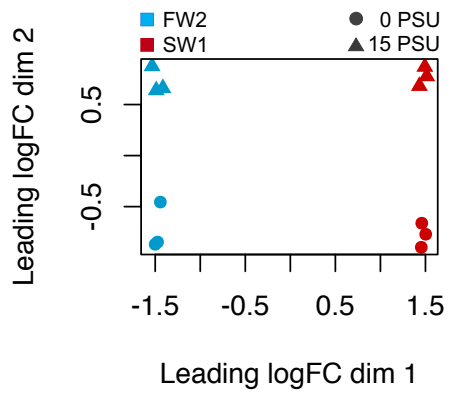

(c) Distance between samples $(n=12)$ based on rlog transformed counts

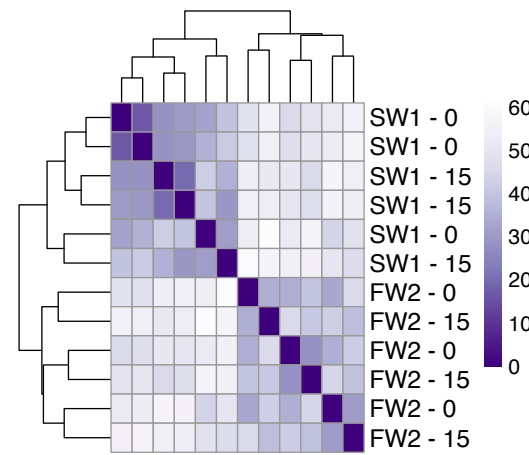

Experiment 2

(b) MDS sample $(n=10)$ clustering based on $\log _{2} \mathrm{FC}$ of top 500 genes

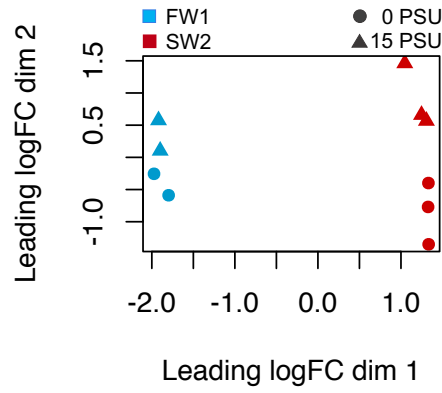

(d) Distance between samples $(n=10)$ based on rlog transformed counts

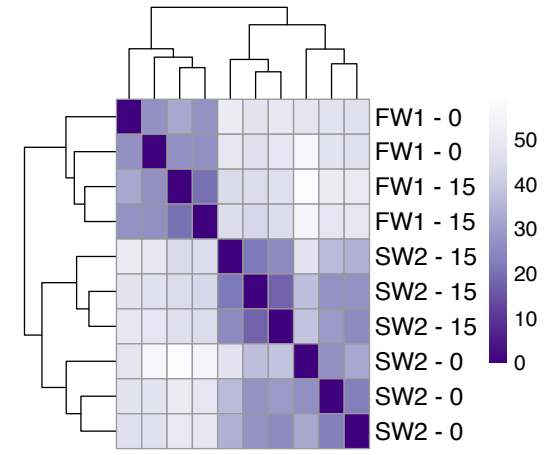


Experiment 1

(a) FW2 vs. SW1 at 0 PSU (3803 DEG)

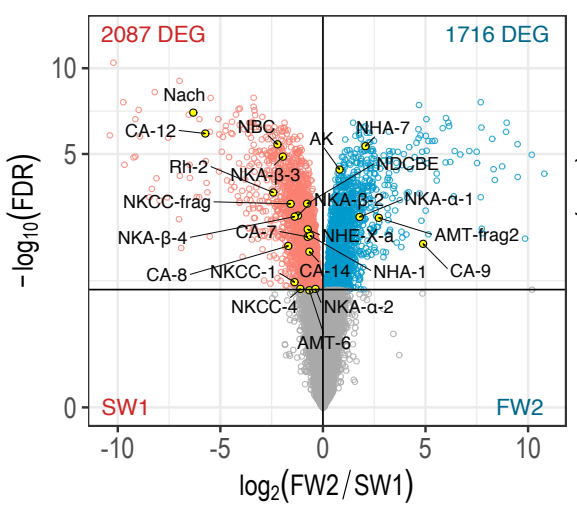

(c) FW2 vs. SW1 at 15 PSU (3920 DEG)

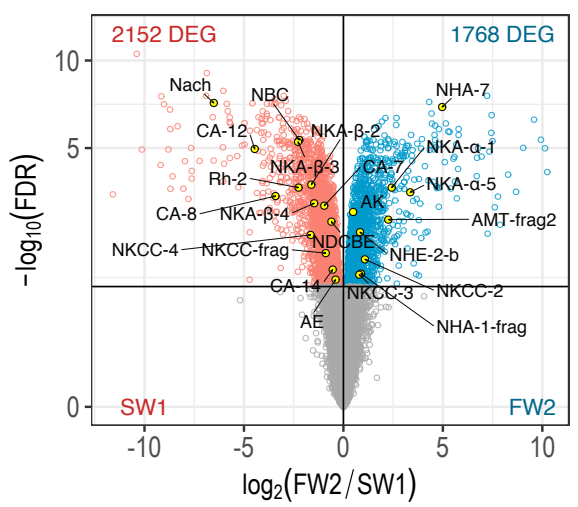

Experiment 2

(b) FW1 vs. SW2 at 0 PSU (3038 DEG)

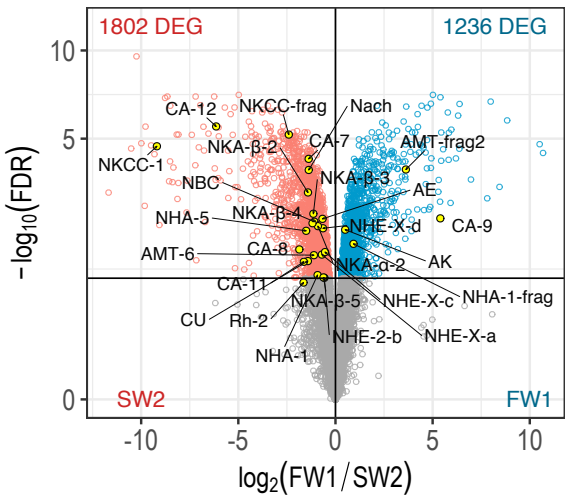

(d) FW1 vs. SW2 at 15 PSU (2673 DEG)

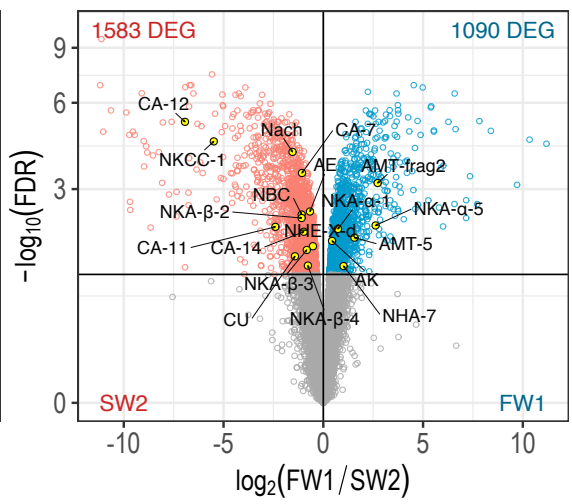


(a) FW vs. SW inbred lines at 0 PSU

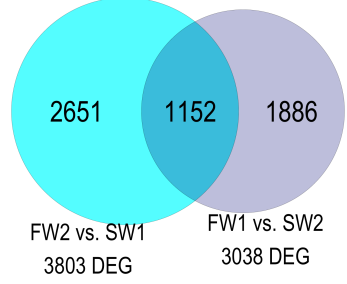

(c) FW vs. SW inbred lines at 0 PSU (1152 DE genes)
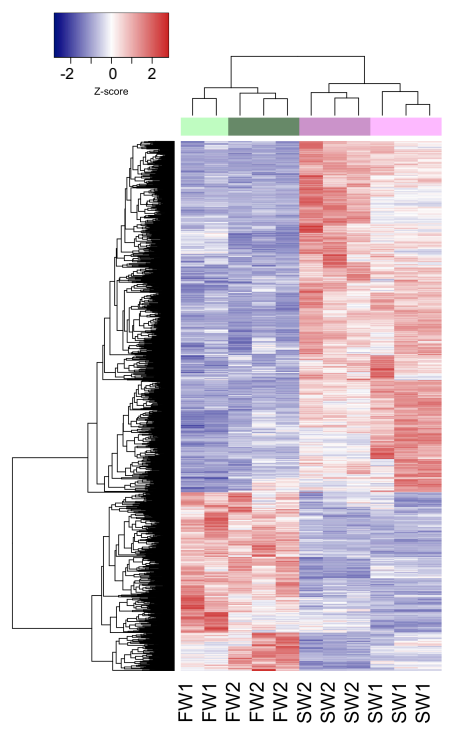

(b) FW vs. SW inbred lines at 15 PSU

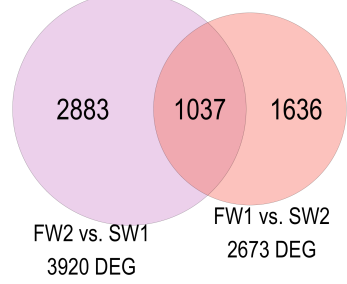

(d) FW vs. SW inbred lines at 15 PSU (1037 DE genes)

\begin{tabular}{|l}
\hline$\square$ FW1 \\
$\square$ FW2 \\
$\square$ SW1 \\
$\square$ SW2
\end{tabular}
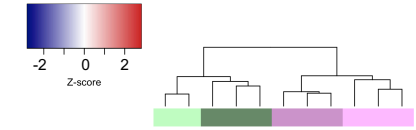

$\begin{array}{ll}\square & \text { FW1 } \\ \square & \text { FW2 } \\ \square & \text { SW1 }\end{array}$

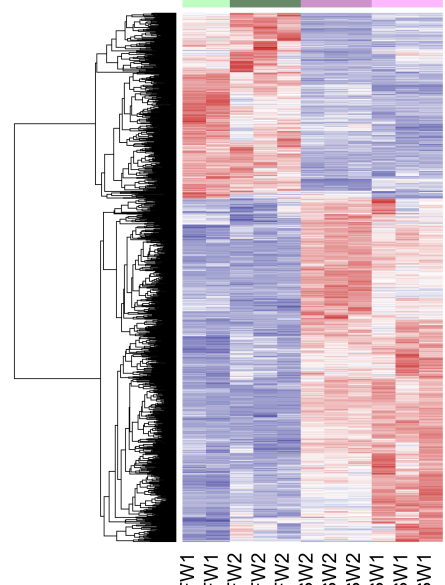


Experiment 1

(a) 0 PSU vs. 15 PSU in FW2 (466 DEG)

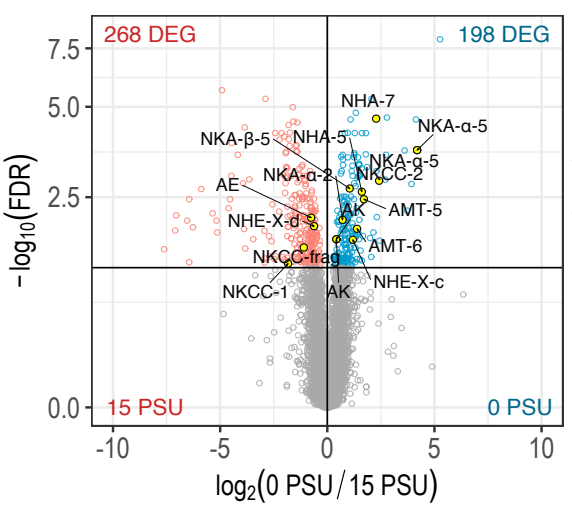

(c) 0 PSU vs. 15 PSU in SW1 (424 DEG)

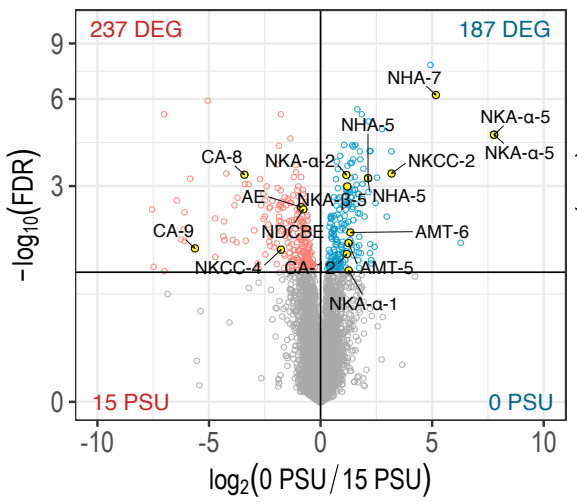

Experiment 2

(b) 0 PSU vs. 15 PSU in FW1 (153 DEG)

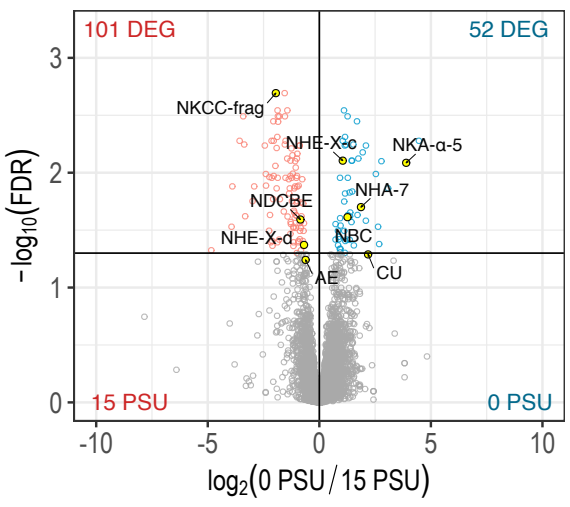

(d) 0 PSU vs. 15 PSU in SW2 (532 DEG)

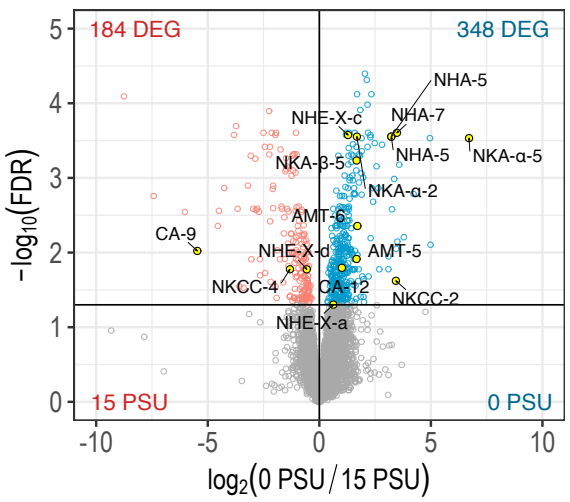




\section{Experiment 1}

(a) All genes $(n=14,082)$

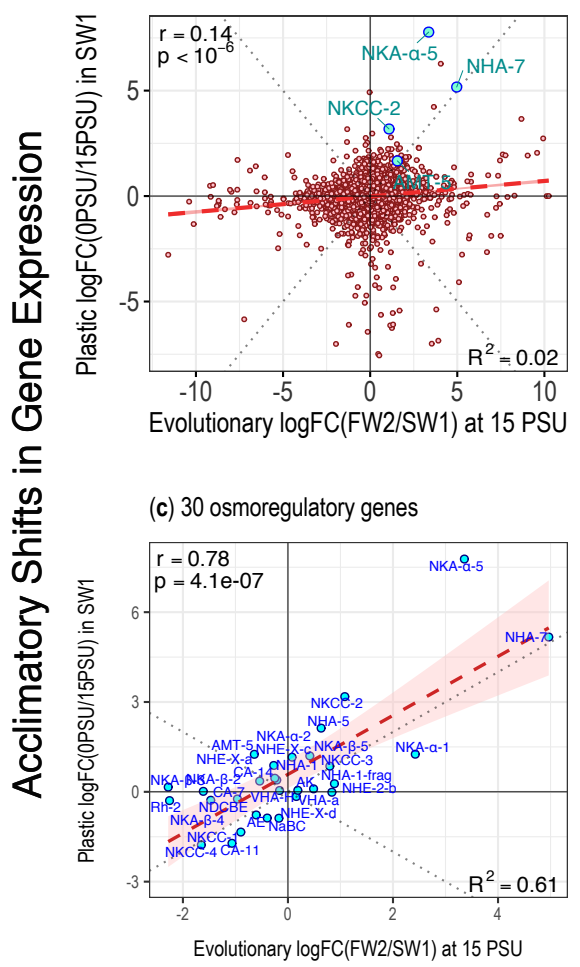

Experiment 2

(b) All genes $(n=14,082)$
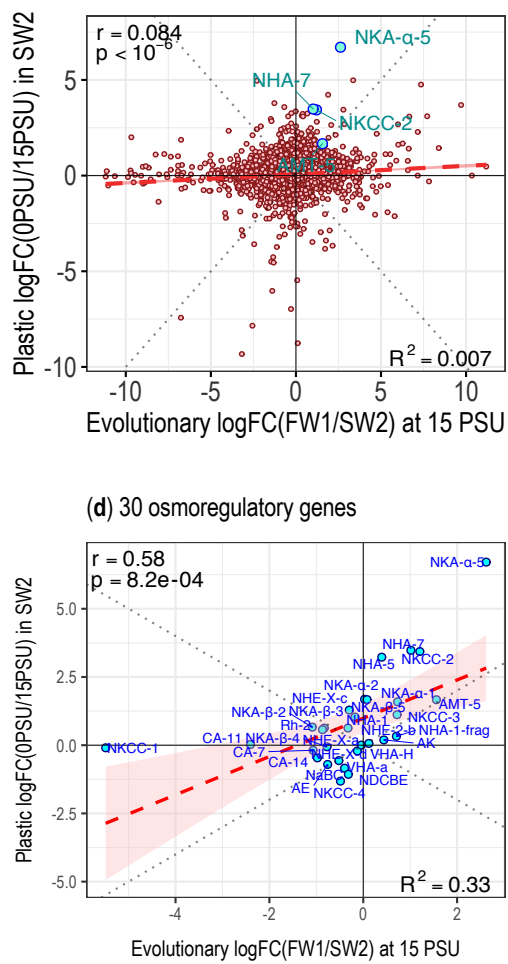

Evolutionary Shifts in Gene Expression 


\section{Experiment 1}

(a) All genes $(n=14,082)$

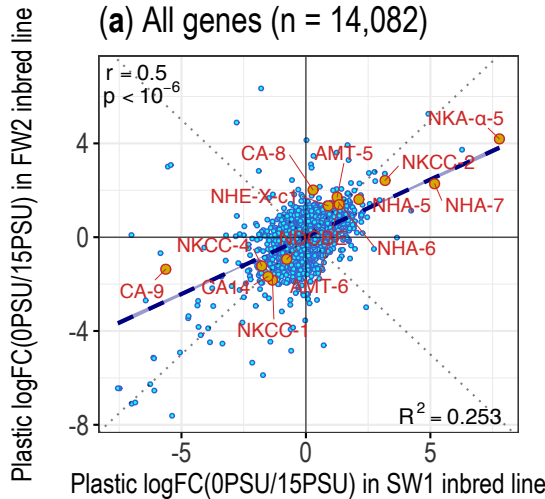

(c) Five osmoregulatory genes

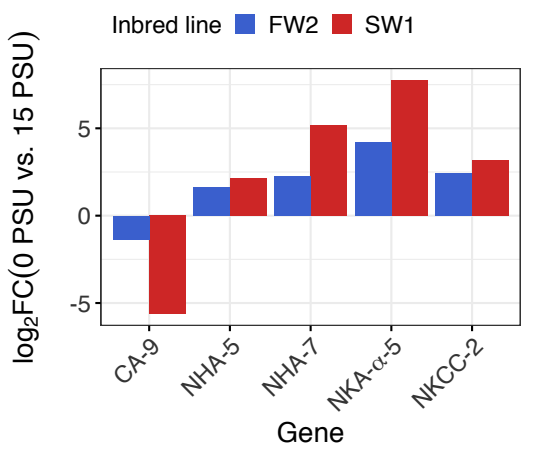

(a) Model 1

$\mathrm{Na}^{+}$Uptake via Electrogenic $\mathrm{NHA}$ or $\mathrm{Na}^{+}$Channel

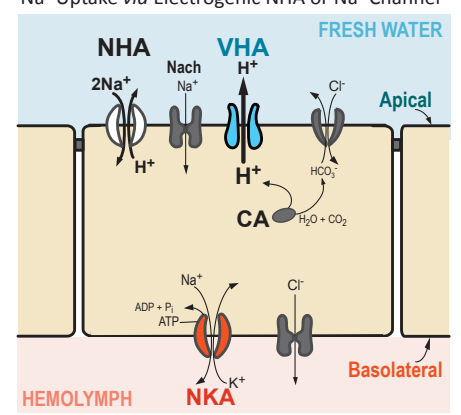

Experiment 2

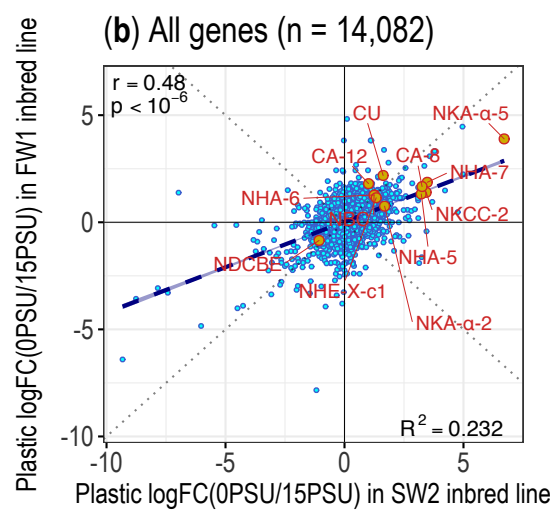

(d) Five osmoregulatory genes

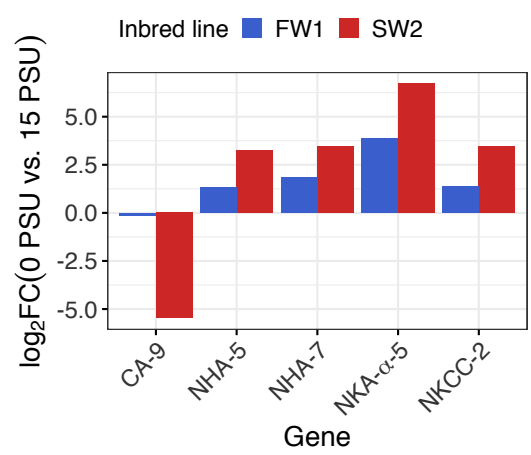

(b) Model 2

$\mathrm{Na}^{+}$Uptake via Electroneutral NHE

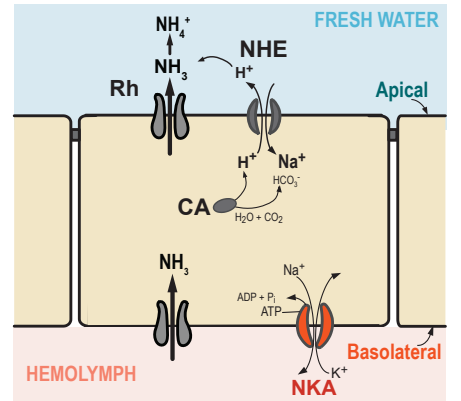

